\title{
Pragmatic reduction of the Binding Conditions revisited
}

\author{
STEPHEN C. LEVINSON \\ Department of Linguistics, University of Cambridge \\ Max Planck Research Group for Cognitive Anthropology, Nijmegen
}

(Received 20 July 1989; revised 17 August 1990)

\section{INTRODUCTION}

In an earlier article (Levinson, $1987 \mathrm{~b}$ ), I raised the possibility that a Gricean theory of implicature might provide a systematic partial reduction of the Binding Conditions; the briefest of outlines is given in Section 2.I below but the argumentation will be found in the earlier article. In this article I want, first, to show how that account might be further justified and extended, but then to introduce a radical alternative. This alternative uses the same pragmatic framework, but gives an account better adjusted to some languages. Finally, I shall attempt to show that both accounts can be combined by taking a diachronic perspective. The attraction of the combined account is that, suddenly, many facts about long-range reflexives and their associated logophoricity fall into place.

I shall dub my earlier reduction the 'A-first' account; the argument is recapitulated in Section 2, but the essential characteristic is that Principle A of the Binding Conditions is taken to be grammatically specified, as in the GB accounts, while Principles $B$ and $\mathrm{C}$ are then reduced to pragmatics (partly in terms of pragmatic 'oppositions' to Principle A patterns). I have come to see a number of internal problems with this account (which I shall mention below), but the main challenge seems to be that in many languages reflexives and pronouns are not always in complementary distribution, and this is especially clear in languages with LONG-RANGE REFLEXIVES. In addition there are languages with no reflexives at all, and yet with Principle B-like patterns of pronominal anaphora, and this obviously poses a problem for an account that makes Principle B-like patterns parasitic on Principle A. These difficulties motivate consideration of a radical alternative, a 'B-first' account, which takes Principle $B$ to be basic (but pragmatic in character) and reduces Principle A- and C-type patterns of anaphora to a parasitic (and pragmatic) status. $^{1}$ It turns out that the B-first account is essential for some

[1] At the time I proposed the A-first account, I had already toyed with the B-first account but could not see how it could be extended to languages with grammaticalized Anaphors and so rejected it entirely. However, Ann Farmer and Robert Harnish impressed me with the possibilities in 1985 (see Farmer \& Harnish, 1987) and Yan Huang's investigations of 
languages - no grammatical account and no A-first kind of pragmatic account seems possible at all. But equally, a B-first account clearly fails where there are grammaticalized Anaphors $;^{2}$ in those languages, an A-first account seems essential. Since the pragmatic apparatus used on both accounts is more or less identical, a typological distinction between the two types of language on the basis of different anaphoric 'strategies' might be appropriate. However, on close examination, A-first languages seem to show evidence of B-first patterns too. This suggests a diachronic progression from B-first patterns to A-first patterns through the gradual grammaticalization of Anaphors. ${ }^{3}$ Some languages, like English, provide direct evidence for such a diachronic account. Various other facts, like the association between longrange reflexives and logophoricity just when the reflexive has no clause-mate antecedent, then acquire an explanation.

Before proceeding further, it may be useful to attempt to place this approach to anaphora, and indeed linguistic explanation generally, in the context of other approaches, in the hope that certain possible misapprehensions can be simply avoided. The kind of approach explored here is to be distinguished sharply from wholesale functional reductionism - there is no inconsistency, for example, between this view and the assumption of rich language universals of biological origin. For the neo-Gricean pragmatic apparatus employed here presumes the independence, or at least partial independence, of syntactic structures and semantic representations (the qualification with respect to semantic representations is necessary for reasons reviewed in Levinson, in prep., ch. 3): computation of pragmatic inferences of these sorts must be made over a level of linguistic representation which includes rich configurational, lexical and semantic information (see e.g. Gazdar, 1979: 56 ff., Levinson, 1983: 122-125). Pragmatics, on this view

Chinese anaphora (1989) over the last three years forced me to reconsider the alternative account. Another catalyst has been Karunavar Mohanan's, Ivan Sag's and David Perlmutter's scepticism about the A-first account, based in part on the lack of complementary distribution of reflexives and pronouns in so many languages. Largely unpublished work by Catherine O'Connor (1987) has also been most helpful in suggesting how the logophoricity facts (so nicely emphasized by Kuno, 1987) should be brought within a pragmatic framework. This paper summarizes lecture four of the 1988 Nijmegen Lectures, to appear as Levinson (in prep.), and I am grateful to that audience for a number of helpful suggestions. Since then I have had further trenchant comments from Yan Huang, Peter Matthews, Nigel Vincent and two anonymous reviewers for which I am most grateful. One of these reviewers, commenting from a GB perspective, produced such useful and incisive comments that I will refer to him or her as 'Bite'.

[2] I shall use the terms ANAPHOR and PRONOUN with systematic ambiguity. With an initial capital they have the technical sense given to them in GB (Anaphors are reflexives and reciprocals; Pronouns are non-reflexive pronominals); otherwise they have the ordinary descriptive linguistic sense (anaphors are anaphoric items; pronouns are reflexive or nonreflexive pronominals - although I will sometimes use the phrase 'plain pronoun', or just 'pronoun', in opposition to reflexives where the context will make the usage clear).

[3] By 'grammaticalization of Anaphors', I here intend the process whereby there is an increasing tendency to read an expression (a) as necessarily referentially dependent, (b) as bound within a restricted domain. 
(which I take to be the standard line), just provides a set of explanatory principles, ancillary to the grammarian's normal armoury, to which the theoretical linguist should always be ready to resort when looking for the simplest explanation for linguistic phenomena. But because pragmatics is the Cinderella of explanatory levels in linguistic theory, nearly all the major theoretical frameworks underestimate the potential for pragmatic explanations of phenomena they treat as semantic or syntactic. Therefore, pragmatic proposals will often be in conflict with syntactic or semantic proposals, as the pragmaticist sees that the pragmatic machinery developed to handle indubitably pragmatic problems may also have application to problems generally held to lie in the province of the grammarian. But it is important to see that such tussles are attempts to re-apportion the burden of explanation, to shift specific phenomena from one kind of linguistic explanation to another, not attempts to undermine the existence of distinct syntactic, semantic and pragmatic levels and modes of explanation, as in some kinds of extreme functionalism. On the other hand, of course, a shift of explanation from grammatical principles to pragmatic ones may be a rather more fundamental change in theory than a shift of explanation from, say, syntactic principles to lexical principles (depending somewhat on the degree to which pragmatic explanations are thought of as strictly nonlinguistic). ${ }^{4}$

In the present instance, the phenomena at stake are certain patterns of intra-sentential anaphora in certain languages. Since many aspects of anaphora (for example, cross-sentential choices of antecedents) are clearly pragmatic in nature, it seems worthwhile to see how far a pragmatic account of intra-sentential anaphora can be pushed, what advantages it has, and whether it may be especially appropriate for particular kinds of language. In some cases, a grammatical account may find itself overlapped by a pragmatic account, and yet the two accounts may be compatible and nonredundant - as when we can find what look like pragmatically motivated patterns which have a syntactic life of their own (a case in point, perhaps, being the Avoid Pronoun Principle). ${ }^{5}$ But in other cases, where the force of the grammatical account is held to lie in the unmotivated (and therefore

[4] For example, if pragmatic principles are conceived of as innate processing tendencies, as in Sperber \& Wilson (1986), they have at least some kinship with innatist accounts of grammatical principles, whereas if they are thought of as rational solutions to problems of communicative co-ordination (as in Grice, 1967, and those who follow him more closely), pragmatic explanations have a rather different ontological and epistemological status. This writer inclines to the latter view (see Levinson, 1989).

[5] Sometimes, GB theorists frankly admit functional motivation (as in the case of the Avoid Pronoun Principle, see Chomsky, 1981:65). Hellan (1988: 142) goes so far as to conclude of the distribution of Anaphors vs. Pronominals in Norwegian, 'the phenomenon of complementarity is part of syntax, even if it is clearly functionally or pragmatically motivated'. But to concede that may be to undermine critically Chomsky's rationalist position. 
presumably innate) character of the relevant patterns, the availability of a pragmatic account, however partial, is more of a challenge. That is the case here, where we offer some partial pragmatic reduction of the Binding Principles at the heart of the Government and Binding theory. Protagonists of that theory will find much to quarrel with in what follows: lack of proper attention to syntactic nuance, to the many alternative possible modifications of the framework, to the possibility of radical parameterization of the Binding Principles, and so on. ${ }^{6}$ But the purpose of the present paper is to present a sketch of an alternative approach to certain central problems of anaphora, which derives part of its interest from the sheer range of apparent explanation over linguistic phylogeny, synchronic generalization and diachronic process, grammar AND meaning, and part from the fact that the mechanisms of explanation were developed for entirely independent phenomena.

\section{THE 'A-FIRST' ACCOUNT: PRAGMATIC REDUCTION OF BINDING CONDITIONS B AND C}

In this section, I briefly recapitulate the argument of Levinson ( $1987 \mathrm{~b}$ ), and show how it might be extended to certain further linguistic phenomena.

\section{I. First approximation to the problem}

A pragmatic account of anaphora begins by noting that anaphoric expressions are usually semantically general. Thus a locally anaphoric (coreferential) reading is encouraged where a more semantically general term like ship follows a more semantically specific term like ferry; and the reverse ordering discourages a locally co-referential reading:

(I) (a) The ferry hit a rock. The ship capsized.

(b) The ship hit a rock. The ferry capsized.

The preference for a locally co-referential interpretation (as in ( $\mathrm{I}$ b)) can be attributed to the Gricean second maxim of Quantity, which I shall call the Informativeness Principle or I-principle for short (see Atlas \& Levinson, I $98 \mathrm{I}$; Levinson, I987a, b). This principle induces maximally informative and cohesive interpretations from minimal linguistic specifications. It is balanced by a Manner maxim or M-principle, which induces from the use of a prolix or marked expression an interpretation that is complementary to the one that

[6] It is not always easy for the pragmaticist to exploit this work, in part because of the tendency to neglect meaning factors, in part because of the sheer detail of alternative, incompatible and sometimes radical revisions of the framework prompted by particular languages. The work on the Germanic languages, Japanese and Chinese is particularly detailed, and will be referred to below. 


\section{REDUCTION OF BINDING CONDITIONS}

would have been induced by the I-principle from the use of a semantically general expression (this is what Horn (1985) calls the 'division of pragmatic labour'). Hence the association of anaphoric potential with pronouns and NP-gaps (both semantically general), and of independent reference with full lexical NPs:?

(2) The general anaphora pattern as $M$ vs. I

lexical NP > pronoun > NP-gap

M-implicates non-co-reference

I-implicates co-reference

A third inferential principle, Grice's first maxim of Quantity (which we shall call the Q-principle), provides a further essential ingredient. This induces a contrastive interpretation between paired expressions of differential semantic strength or informativeness. For example, the pair of quantifiers 〈all, some > form a Horn-scale of this kind, such that the use of the semantically weaker some (as in some of the boys came) Q-implicates the inapplicability of the stronger all, to yield the interpretation 'not all of the boys came'. Only linguistic expressions that meet certain criteria - notably salient opposition - form such Horn-scales capable of giving rise to such Qimplicatures (see Atlas \& Levinson, 198I). One such salient contrast is the opposition between ordinary pronouns and reflexives (see Levinson, $1987 \mathrm{~b}$, for justification):

(3) The contrast 〈REFLEXIVE, PRONOUN〉 forms a Horn-scale, so that the use of the Pronoun Q-implicates that the stronger Reflexive could not truthfully have been used.

A final ingredient in the pragmatic account is a projection rule for generalized conversational implicatures, to the effect that, when inconsistent implicatures arise, priority is given according to the following hierarchy: $\mathrm{Q}>\mathrm{M}>\mathrm{II}^{8}$ Thus any tendency to read a pronoun as locally co-referential by the I-Principle will be over-ruled by a Q-implicature to disjoint reference just where a stronger reflexive could have been used to express co-reference.

A point that needs to be stressed (in the light of current fashions in pragmatics) is that it is a special kind of implicature that is involved in these generalizations, namely GENERALIZED conversational implicature (or GCIs for short). GCIs are default interpretations, or preferred readings, in short properties of utterance-types not utterance-tokens. They are generated by

[7] Compare the anaphoricity scale in Lakoff (1968), discussed in Koster (1986: 352 f.).

[8] The hierarchy of $Q$ over $I$, and $M$ over $I$ is motivated by a great deal of data, although the relative ordering of $Q>M$ is not so firm. The underlying rationale, Chris Pinon has suggested to me, is that (a) linguistic oppositions (as in $Q$ and $M$ ) take precedence over inferences based partly on knowledge of stereotypes, while (b) inferences based on semantic 'strength' $(\mathrm{Q})$ takes precedence over those based on superficial form (M). See Atlas \& Levinson (1981), Horn (1985), Levinson (1987 b), Levinson in prep. Ch. 2. 
certain stable interpretive heuristics, not by nonce-inference of the sort promoted in Relevance-theory or many kinds of computational pragmatics (see Levinson, 1989). Thus GCIs are stable, but defeasible, tendencies of interpretation; in other words, just the sorts of things easily mistaken for grammatical stipulations.

We now have an incipient reduction of some aspects of the Binding Conditions, which are classically formulated as in (4):

\section{(4) Binding Conditions}

(A) Anaphors (reflexives and reciprocals) must be bound in their governing category.

(B) (Non-reflexive) Pronouns must be free in their governing category.

(C) A lexical NP must be free everywhere.

The argument goes as follows:

(a) Where the syntax permits, a speaker intending co-reference should use an Anaphor by the Q-principle; the use of the weaker Pronoun will Qimplicate disjoint reference by the Horn-scale 〈REFLEXIVE, PRONOUN >;

(b) Otherwise, where a semantically general expression (e.g. a Pronoun) is used, it will I-implicate local co-reference UNLESS:

(i) an Anaphor (e.g. reflexive) could have been used;

(ii) a prolix form has been used which will M-implicate the complement of the I-interpretation from a reduced form.

Thus in (5a) the preferred interpretation is that the NPs are disjoint (a reflexive could have been used as in $\left(5 \mathrm{a}^{\prime}\right)$; the non-use of a reflexive pronoun Q-implicates that the reflexive interpretation is not intended); in (5b) the pronoun he cannot give rise to a $\mathrm{Q}$-implicature of disjointness (since a reflexive could not be used in this position $-\left(5 b^{\prime}\right)$ is ungrammatical), so there is no higher-priority implicature to cancel the I-inference to co-reference; in $(5 \mathrm{c})$ the expression the man is prolix by contrast to he, thus M-implicating disjointness.

(5) (a) John ${ }_{1}$ likes him

(a') John 1 likes himself

(b) John $\mathrm{J}_{1}$ told her ${ }_{2}$ that he ${ }_{1}$ gave her ${ }_{2}$ a valentine.

(b') ${ }^{*} \mathrm{John}_{1}$ told her ${ }_{2}$ that himself ${ }_{1}$ gave her $_{2}$ a valentine

(c) John told her $_{2}$ that the $\operatorname{man}_{3}$ gave her $_{2}$ a valentine.

In this way, the Binding Conditions are reduced, at a level of first approximation, as follows: 


\section{REDUCTION OF BINDING CONDITIONS}

\section{(6) Partial reduction of the Binding Conditions}

BINDING CONDITION A:

Content: 'Anaphors (reflexives and reciprocals) are 'bound' (coindexed with a c-commanding NP) in their minimal governing category'.

Pragmatic account: Nil

BINDING CONDITION B:

Content: 'Pronouns must be free (not co-indexed with a ccommanding NP) in their minimal governing category'.

Pragmatic account: Given a Horn-scale pair like 〈himself, him $\rangle$, use of the weaker, less specific him will Q-implicate disjoint reference wherever the reflexive could have been used (if you had meant the stronger, more specific co-referential sub-case, you should have used the form that encodes co-reference).

BINDING CONDITION C:

Content: 'Lexical NPs must be free (not co-indexed with a ccommanding NP) throughout the sentence'.

Pragmatic account: two parts:

(i) just as in B, there will be a Horn-scale-like opposition between, say, 〈himself, the man〉, such that wherever a speaker could have used a reflexive he/she should have if co-reference is intended;

(ii) unlike $\mathrm{B}$, there will be a further opposition between the potential use of the pronoun and the use of a lexical NP: \{he, the man are opposed by Horn's (1985) Division of Labour: $\mathrm{He}$, being a minimal form, will encourage an I-inference to local coreference; the man (etc.) will $\mathrm{M}$-implicate disjoint reference, since the speaker would seem to be avoiding the I-implicatures induced by the pronoun.

This is obviously only a partial reduction because Binding Principle A is simply accepted as a rule of grammar; but then Binding B is given to us as a 'mirror-image' pattern by the Q-principle, while Binding $\mathrm{C}$ is given by the same principle PLUS the M-principle yielding complementary interpretations from the use of prolix expressions. In addition, nothing is said about the empty categories NP-trace and wh-trace which on the GB account are assimilated to the same Binding patterns; a pragmatic account is likely to treat these as largely independent, perhaps irreducibly syntactic, issues. ${ }^{9}$

The reduction is also only partial in another sense: it fails to predict the

[9] But the interpretation of at least some gaps (especially perhaps those treated as PRO within the GB framework) falls naturally under the same pragmatic principles (see for example Levinson, $1987 \mathrm{a}, \mathrm{b}$ and references therein). 
following sort of alternation that seems to rely on some notion of configurational dominance:

(7) (a) Next to him ${ }_{1}, \mathrm{John}_{1}$ saw a snake (co-reference OK)

(b) ??Next to $\mathrm{John}_{1}$, he ${ }_{1}$ saw a snake (co-reference bad)

In the earlier paper, I suggested that we might here adopt Reinhart's (I983) proposal that builds another kind of anaphoric pattern into an expanded Principle A (expanded to incorporate one aspect of Principle C). Reinhart suggests that the pattern NP-c-commanding-Pronoun always allows the pronoun to be treated as a bound variable (person-number-gender features permitting), just as (on her account) a reflexive is a bound variable. Then we will get a second 'mirror-image' inference by the Q-principle; namely, wherever a Pronoun-c-commanding-lexical NP pattern is used, there will be a presumption of disjoint reference. Thus any speaker intending co-reference should use (7a) and not (7b). Such a further bit of grammatical machinery might be required for some languages like English, I suggested, tut not, it seems, for others like the Australian language Guugu Yimidhirr that I was describing in that earlier paper (which lacks a strong opposition between sentences corresponding to $(7 \mathrm{a}, \mathrm{b})$ ). I also noted that one might try to avoid building in this extra grammatical machinery by adopting some version of Bolinger's maxim 'Don't reintroduce (i.e. lexically specify) the topic of the theme in the rheme'. Van Valin (1990) now urges such a solution on us, pointing out that the two pragmatic traditions (the Griceans on the one hand, and the 'functionalists' with their orientation to the Prague school functional sentence perspective, on the other) promote compatible and complementary views.

Bolinger's maxim works well (as Reinhart acknowledges) for examples like $(8 \mathrm{a}, \mathrm{b})$. Co-reference is odd in ( $8 \mathrm{a})$ because the topic is 'reintroduced' as a full NP in the rheme; it is alright in ( $8 b)$ because her is only part of the topic her mother, thus the ban on reintroduction does not apply. However, a problem for Bolinger's solution, Reinhart (1983) points out, is that it fails to say anything about the opposition between $(8 \mathrm{c})$ and $(8 \mathrm{~d})$ since the coreference in question here (between him and Ben) is all within the rheme.

(8) (a) ??She ${ }_{1}$ thinks $\mathrm{Mimi}_{1}$ is adorable

(b) $\mathrm{Her}_{1}$ mother thinks $\mathrm{Mimi}_{1}$ is adorable

(c) ??Mimi locked him in Ben's $_{1}$ room

(d) Mimi locked Ben ${ }_{1}$ in his, room

But here perhaps there is a possible extension of Bolinger's account, in terms of a distinction between rhematic core and periphery, with a second maxim 'If a topic is introduced in the rhematic core, don't reintroduce it in the rhematic periphery'. Alternatively, and perhaps more convincingly, one may need to note that when a verb subcategorizes for a number of non-subject arguments, the thematic role hierarchies that hold over these arguments restrict co-reference possibilities. Thus assuming that Patient is higher than 
Goal in such a hierarchy, and presuming a maxim of the sort 'Don't reintroduce an NP in a lower-ranked thematic role', him and Ben in $(8 \mathrm{c})$ would resist a co-referential interpretation. Van Valin is surely right that we should explore such lines of explanation further; meanwhile I shall remain agnostic between such a pragmatic account of the apparently configurational constraints and Reinhart's type of solution. ${ }^{10}$

\subsection{Problems for an A-first account}

Various problems with such a reduction of the Binding Conditions have become clear. There is obviously room for doubt of various kinds about the internal argumentation. One may for example doubt that pronouns and reflexives really form Horn-scales. If one adopts the Reinhart account of the configurational asymmetries, one may further doubt whether the opposition between constructions (NP-c-commanding-Pronoun vs. Pronoun-c-commanding-lexical $N P$ ) would really be sufficient to engender a Q-opposition of the right kind. Both these doubts can be alleviated, for reasons I give elsewhere (Levinson, in prep., ch. 4). Similarly, doubts about whether these patterns of co-reference are too firm to be pragmatically induced can I think be convincingly assuaged by examining the many circumstances under which the 'banned' interpretations are in fact possible. For example, it is obvious that there is a large class of cases where functional requirements over-ride any preference for clausemate reflexives: ( $9 a$ ) is informative in a way in which $(9 b)$ is not. Similarly, although the preference for disjoint readings of pronouns-c-commanding-lexical NPs is indeed strong, as illustrated by the tendency to read the initial $\mathrm{He}$ and John as distinct in reference in (9c), again the preference is quite naturally over-ridden in ( $9 \mathrm{~d})$ :

(9) (a) The Prime Minister is Margaret Thatcher.

(b) The Prime Minister is herself.

(c) He's doing what John told him to do.

(d) He's doing what John always does.

[10] Many difficulties remain for such a pragmatic approach. For example, the anonymous reviewer I am calling 'Bite' points out that in the following examples, only (b) and (d) are acceptable, as predicted by the c-command analysis, despite the reversal of thematic roles:

(a) *We gave him John's $_{\mathrm{i}}$ mother

(b) We gave $\mathrm{John}_{\mathrm{i}}$ his $_{1}$ mother

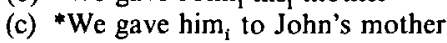

(d) We gave John ${ }_{i}$ to his mother.

On the other hand, the range of Principle $\mathrm{C}$ violations exhibits a clear gradation of acceptability, and this, together with the relative lack of theoretical motivation, leads e.g. Koster (1986: $346-356$ ) to propose that the effects are purely pragmatic but sensitive to syntactic criteria (like c-command) that give differing degrees of prominence to NPs. Further, language acquisition data (reviewed in Lust, 1986: $82 \mathrm{f}$.) shows this c-command pattern of constraints on anaphora to be learnt very late, and subject to pragmatic overriding, which again suggests a functional source. 
The example in (9d) (drawn to my attention by Ivan Sag but due originally to Bolinger) is interesting because not only do we have co-referentiality between John and the c-commanding pronoun, but the pronoun is referentially dependent on the name. It is not the kind of example where the reference of the pronoun has to be antecedently given and thus the pronoun can be held to be accidentally (or independently) co-referential with the name. ${ }^{11}$ Again, I must leave the elaboration of these issues for elsewhere.

There are however a number of basic empirical facts that do seem to challenge a theory of this kind. The first is the neglected but indubitable fact that there are a number of languages which lack grammatical reflexives altogether, and which nevertheless exhibit a preference for clausemate disjointness of pronominal NPs (i.e. a Principle B-like pattern). This is puzzling on my account because, as already stated, the A-first account makes Principle B-like patterns arise as 'mirror-image' inferences from a Principle A; but such languages clearly have no Principle A as they have no Anaphors. The facts about these languages have simply not been properly considered in nearly all the recent theorizing about anaphora, and yet they seriously undermine all existing accounts. Because of the neglect, I discuss some of the basic facts in Section 3 below.

Another range of facts that do not seem to fit well with the A-first account are the many exceptions to the tendency for Anaphors and Pronominals to be in complementary distribution. ${ }^{12}$ Sometimes either a reflexive or a pronoun can be used without making an apparent difference in reference: in short, in some locations the opposition in anaphoric potential is neutralized. Although the phenomenon is most prominent in other languages, its occurrence in English has also been much discussed, and recently in depth by Kuno (1987). For example, although there is a difference between (IOa), which requires co-reference, and (IOb), which permits it, in both cases the natural interpretation is the same as far as reference is concerned $:^{13}$

(Io) (a) John pulled the blanket towards himself.

(b) John ${ }_{1}$ pulled the blanket towards him

[I I] Consider:

A: 'How was the international chess match?'

B: 'Oh they $y_{1}$ went and did what the Russians, always do and won every single game' Or (after Koster, $1986: 347$, after Bolinger):

A: 'What did you do for Christmas?'

B: 'We gave her ${ }_{1}$ the Italian holiday our daughter, always wanted to have.'

[12] I am grateful to K. Mohanan for insisting on proper attention to this issue.

[13] Peter Matthews points out to me that in cases like (JOb) there may be a systematic prosodic difference between unstressed him (non-co-referential) and stressed him ('reflexive'). Although such a prosodic marking is natural, I am not sure it is essential; indeed, to make a Matthewsian point, since prosodic features are continuous and the interpretive feature in question binary, it would seem unlikely that stress could be more than one available mode of directing a recipient towards a 'disambiguation'. In any case, in the analysis to be outlined in Section 3, marked (including stressed) NPs are claimed to M-implicate the complementary interpretation to that which would arise from the use of the corresponding unmarked $\mathrm{NP}$ - thus the observation falls within the theory. 


\section{REDUCTION OF BINDING CONDITIONS}

Obviously, such cases are a serious difficulty for a GB account which has the same definition of governing category for both Anaphors and Pronouns, thus requiring that wherever a reflexive can occur co-referential with a specific antecedent, a pronoun must be construed as disjoint in reference to the same antecedent. It is equally clear that they may pose a problem for our pragmatic account: what happens to the alleged Q-inference from the use of the pronoun to the inapplicability of the reflexive?

A pragmatic account, however, is not necessarily embarrassed by the failure of such complementary distribution, for the Q-inference to disjoint reference is only a defeasible implicature. Thus if we can show that there are systematic reasons why the implicature should be cancelled in just these cases, no problems will arise. In many cases such an explanation would seem to be correct. It may be useful to divide the cases into two classes: those where the Q-implicature fails to arise because the semantic basis for it does not obtain, and those where inconsistent background knowledge (as always) cancels the preferred interpretation.

In the first class, the Q-implicature normally arising from the Horn-scale 〈REFLEXIVE, PRONOUN〉 may fail to arise where these alternatives are no longer ordered by semantic informativeness. For example, in cases like (I I) and (12) (after Reinhart, 1983), the (a) sentences with Anaphors clearly have different truth-conditions from the (b) sentences with Pronouns: (I I a) may describe a situation in which Felix got many votes but he was the only candidate who voted for himself, while (I $\mathrm{b}$ ) necessarily describes a situation in which Felix only got one vote (his own). Similarly, (12a) may describe a situation where each boy likes all the books other than his own, while ( 12 b) requires that each boy likes all the books, or at least his own.

(II) (a) Only Felix voted for himself.

(b) Only Felix ${ }_{1}$ voted for him $1 /$ Felix $_{1}$

(12) (a) The boys like each other's books.

(b) The boys ${ }_{1}$ like their ${ }_{1}$ books

The different truth-conditions clearly stem from the difference between Pronominals and Anaphors under quantification (note though that matters are far from simple, the pronoun in (IIb) resisting treatment as a bound variable, that in (12b) encouraging it). But whatever the source for the difference in truth-conditions, it is clear that in these exceptional cases the sentences with the plain pronouns are potentially MORE INFORMATIVE than the sentences with the reflexives, that is to say they describe more restrictive circumstances. Thus the scale of informativeness responsible for Q-implicatures does not apply here. Or to put the matter another way, the truth-conditional differences will warrant the use of a co-referential clausemate pronoun: where a speaker might wish to express a particular proposition which requires a co-referential interpretation which would not 
be available if a reflexive were used, the use of a pronoun will not necessarily suggest a disjoint reading. ${ }^{14}$

The other class of systematic exceptions are those where background knowledge over-rides a preferential interpretation. Example (Io) above may be a case in point. In order for John to pull a blanket towards some third party, and assuming that the blanket is to be used as a cover in the normal way, he must naturally be behind that party; but then it is unlikely that he can reach it. Thus there is a temptation to read John and him as coreferential, despite the fact that a reflexive might have been used instead. That this is more a matter of likely scenario than anything else is shown by altering the lexical content, so that the normal preferential interpretation reappears:

(I3) (a) John directed the missile towards himself.

(b) ?? John directed the missile towards him $_{1}$

So, in many cases, we may be able to argue that the Q-Implicature never arises or arises but is cancelled by inconsistent assumptions. And such arguments would favour the pragmatic approach to disjoint reference since we would in each case be dealing with a principled defeasibility. However, such a piecemeal approach proves unconvincing once the widespread nature of this failure of complementary distribution is appreciated. Thus we need to consider the possibility of a more general account, one that can handle what in many cases looks like genuine neutralization. ${ }^{15}$

[14] Examples like (11) are generally agreed to pose serious problems for a configurational account of disjoint reference conditions (cf. for example Hellan, 1988: 140). Nevertheless one might attempt (after Higginbotham, 1980: $697 \mathrm{f}$. and 'Bite') such an account as follows: in ( 11 a) the quantified phrase Only Felix, but not the NP Felix, c-commands the reflexive, allowing the bound-variable reading; so too in ( $\mathrm{I} b$ b) the pronoun is not ccommanded by Felix, and so is not bound but free. Much depends here on the construal of c-command of course, but regardless of that, one can find adverbial or conjunctive paraphrases of only that make it clear that the overlapping distribution of Pronoun vs. Anaphor is determined by the need to make a meaning distinction, not by configurational rules, as in the following alternatives to (I I):

(i) (a) (No-one else in the committee wanted to vote for Felix.) Alone of all the committee members, Felix ${ }_{1}$ voted for himself . $_{1}$.

(b) (No-one else in the committee wanted to vote for Felix.) Alone of all the committee members, Felix ${ }_{1}$ voted for him 1 .

(ii) (a) (No-one else in the committee wanted to vote for Felix but) Felix ${ }_{1}$ voted for himself ${ }_{1}$ and was the only person to do so.

(b) (No-one else in the committee wanted to vote for Felix but) Felix 1 voted for him $_{1}$ and was the only person to do so.

[15] 'Bite' points out that the possibilities of a syntactic basis for this neutralization have not been exhausted. For example, suppose that locative/directional PPs may optionally have implicit subjects (as argued for nominals by Chomsky, 1986: $167 \mathrm{ff}$.), then towards him in (10) may optionally have the subject blanket, in which case him is free (as required by Binding Condition B) even when understood as co-referential with John. Where the PP is not construed as having an implicit subject, co-reference must be indicated by the reflexive, as required by Binding Condition A. This syntactic PP-ambiguity, carrying with it alternations of Pronoun vs. Anaphor, might then be the structural basis for the semantic nuances that Kuno and others have attributed directly to a choice between Pronoun and 


\subsection{Q-contrasts and logophoricity}

The problem, then, is how to explain the apparent true neutralization between plain pronoun and reflexive in cases like the following, where, despite the fact that the reflexive is necessarily referentially dependent and the pronoun only optionally so, we tend to assign the same reference to both:

(14) (a) John found a snake near him/himself

(b) He spilled the milk all over him/himself

(c) He wrapped the cloak around him/himself

We should note that not only do we obtain pronouns where we expect reflexives because of clausemate antecedents (as in (I4)), but we also sometimes find reflexives where we expect plain pronouns, with antecedents beyond the immediate clause (let us call these LONG-RANGE REFLEXIVES): ${ }^{18}$

(15) (a) John thought that Mary criticized everyone but himself/him (Keenan, 1987)

(b) Mary said to John that she knew that the paper had been written by Ann and himself/him (Ross, 1970)

(c) Mary said to John that there was a picture of himself/him in the newspaper (Kuno, 1987)

The grammarians have been hard at work to explain such cases, but Kuno (1987) argues convincingly that no existing syntactic account is successful. Instead, he points out that there are subtle meaning differences expressed by choosing a pronoun or a reflexive in these cases. Thus the neutralization is only at the level of reference; there remains a semantic/pragmatic contrast. For example, turning first to the case of clausemate co-referential pronouns, Kuno points out that ( $16 \mathrm{a}$ ) suggests that John lifted up the book and put it behind him, whereas ( $16 \mathrm{~b}$ ) suggests rather that John manoeuvred himself between the viewer and the book.

Anaphor. Obviously, such an account cannot be ruled out; equally clearly it will not generalize to explain the similar semantic/pragmatic nuances associated with 'long range reflexives' to be discussed below.

[16] The terms 'long distance binding' (Chomsky, 1986: 174), 'long reflexivization' (Everaert, 1986: ch. 8), 'non-clause bound reftexivization (NCBR)' (Anderson, I986: $68 \mathrm{ff}$.), and the like have been used often without clear definition. From a GB point of view, one needs to distinguish the more general case where reflexives are bound outside their governing category, from the sub-case where they are bound across an S-boundary (and within the latter, across S vs- S-bar, tensed vs. untensed, subjunctive vs. indicative INFL, etc.). From a pre-theoretical point of view, one needs perhaps to distinguish at least the three cases: (a) where reflexive and antecedent are both subcategorized arguments of the verb ('short reflexivization ' perhaps); (b) where reflexive and antecedent are within the same clause, but the reflexive is in an adjunct phrase like a PP; (c) where reflexive and antecedent lie in different clauses ('long reflexivization' proper or NCBR). (Foley \& Van Valin's (1983) typology of junctures might bring more precision here.) Although the (c) class is the focus of what follows, the (b) class is clearly intermediate and needs to be brought into the picture. 
(I6) (a) John hid the book behind him.

(b) John hid the book behind himself.

Similarly, turning to the case of the long-range reflexives, Kuno draws attention to a more general kind of meaning difference:

(17) (a) Mary said to John that there was a picture of himself in the newspaper.

(b) Mary said to John that there was a picture of him in the newspaper.

(c) ?? Mary said of John that there was a picture of himself in the newspaper.

(d) Mary said of John that there was a picture of him in the newspaper.

Kuno suggests that the meaning difference between ( $17 a)$ and $(17 b)$ is essentially one of POINT OF VIEW: the use of the reflexive obliges us to take John's point of view, while the use of the pronoun allows the normal, deictic, objective point of view. ${ }^{17}$ That this is what is involved is shown by the opposition between $(\mathrm{I} 7 \mathrm{c}$ ) and $(\mathrm{I} 7 \mathrm{~d})$ : here the matrix predicate said of forces the objective point of view (because John cannot be part of the reported event), and hence the reflexive is odd. Looking back at the cases where pronouns can be used with clausemate antecedents, the same general opposition is often clear:

(18) (a) He pushed the brandy away from him.

(b) He pushed the brandy away from himself.

(I 8 a) invokes a 'camera angle' from across the room as it were, while ( $18 \mathrm{~b}$ ) invokes a 'camera angle' from the protagonist's own viewpoint. ${ }^{18}$

Now this association of a subtle meaning difference in 'point of view' with long-range reflexives is a phenomenon reported in much recent research on a great range of languages often under the rubric of LOGOPHORICITY. The concept of logophoricity was developed by Hagège (1974) in response to the phenomenon in African languages like Ewe, Tuburi and Mundang where there are special anaphoric pronouns (sometimes with additional verbal

[17] For some earlier interesting observations here, see Cantrall, 1974, who emphasized the empathetic flavour of long range reflexives, thus explaining the following kind of example (p. 44): I can understand a father wanting his daughter to be like himself but I can't understand that ugly brute wanting his daughter to be like him!

[18] There must be some doubt, 'Bite' points out to me, that all these classes of cases should really be handled by the same theory. Against assimilating reflexives in PPs and picture NPs with the 'long-range' reflexives, there are some tendencies to locality restrictions in the former cases (as predicted for example by Chomsky, 1986: $164 \mathrm{ff}$.) and not in the latter. Perhaps intuitions differ, but the following kind of example (with an intervening thematic subject) seems to me to undermine this possible contrast:

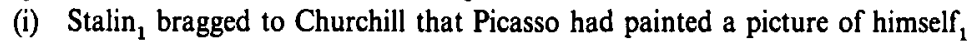




\section{REDUCTION OF BINDING CONDITIONS}

affixes) which refer to an antecedent from whose point of view events are being described. Such pronouns are necessarily referentially dependent and in this respect are just like reflexives, but unlike the items normally referred to as long-distance reflexives, they cannot occur with clausemate antecedents. In both cases, however, it is systematically reported that the logophoric pronoun or long-distance reflexive is optional. In other words, a plain pronoun can be used instead with identical (co)-reference (see Stirling, I 988 : ch. 7 for details). It is the long-distance reflexives that interest us here just because they occur both 'short-range' (with clausemate antecedents) and 'long-range' (with antecedents beyond the clause), and there has been much work on such reflexives, especially in Icelandic and other Germanic languages, Chinese and Japanese. ${ }^{19}$

A serious review of this work is beyond the scope of this paper, but the basic phenomenon can be illustrated as follows. If we use self as a gloss for the reflexive in these languages, then the distribution of the reflexive is illustrated by the English glosses in (19):

(19) (a) John hit self.

(b) John said that self would come.

(c) John said that Bill would hit self.

Some instantiations of these sorts of patterns, drawn from Kuno's (1987) discussion, follow:

(20) Latin (from Kuno, 1987: 137)

Petierunt ut sibi liceret

begged-3PL that to-themselves be-allowed

'They begged that it might be allowed to them'

(21) Japanese (ibid.)

Taroo wa zibun ga tensei da to omotte iru self genius is that thinking is

Taroo [self a genius is] thinks

' Taroo $_{1}$ thinks that he's a genius,

(22) Korean (ibid. 139)

John-i Bill-eykey caki-ka am-i-la-ko malhayssta

John-NOM Bill-DATIVE self-NOM cancer-be-that said

John to Bill [that self has cancer] said

'John ${ }_{1}$ said to Bill that he ${ }_{1}$ has cancer'

[19] See for example Yang (1983), Sells, Zaenen \& Zec (1987), Kuno (1987) for general references; Everaert (1986), Hellan (1988), Hellan \& Christensen (1986) and references therein for Germanic; Kuno (1987), Sells (1987) and their references for Japanese; Huang (1983), Battistella (1985, 1989), Y. Huang (1989) and references for Chinese. 
(23) Icelandic (ibid. 14I; Maling, I984)

Jon segir ath Haraldur viti ath Maria elski sig Jon says that Harald knows + SUBJv that Maria loves self 'John $n_{1}$ says that Harald knows that Mary loves him ${ }_{1}$ '

As mentioned, in nearly all the languages for which we have reports, a nonreflexive pronoun can be used with the same reference in the same or similar environment. ${ }^{20}$ From a GB perspective, this at least requires that Principle $\mathrm{A}$ and Principle $B$ of the Binding Conditions operate with distinct but overlapping binding domains. However, a problem for that solution is that in a number of these patterns the reflexive can take an antecedent beyond, sometimes way beyond as in (23), the nearest accessible subject. Thus we are faced with Anaphors (if such they are) with apparently unlimited binding domains. The syntactic constraints then border on the vacuous and we are left with what really amounts to little more than the semantic restriction of necessary referential dependence.

The data are complex, and in various ways diverse, so it is still not clear how similar the patterns are across languages. For example, there is obviously an important distinction between those languages that permit long-range reflexives in subject position (like Chinese, Japanese, Korean) and those (like some of the Germanic languages) ${ }^{21}$ that do not. Further, some languages (like the Germanic ones) have more than one reflexive form, only one of which participates in long-distance reflexivization, and which are subject to constraints that vary in intricate ways across the Germanic languages (see for example Everaert, 1986: 212 ff.; Hellan, 1988: ch. 2 and my footnote 28). Nevertheless, one clear generalization does seem to emerge, and that is that these long-range reflexives seem to be closely associated with (what may be loosely called) a 'logophoric' point of view, that is to say with the subjective perspective of the referent of the antecedent of the reflexive.

Attempts have been made (by Sells, 1987 and Stirling, 1988 among others) to distinguish different aspects of this semantic nuance. Sells (1987) factors out the following semantic ingredients: the relativization of deixis to a particular protagonist's (the PIVOT's) point of view, the point of view of a reported speaker (the SOURCE), and the protagonist from whose mental perspective an event is being reported (the SELF). In the prototypical

[20] Sometimes the logophoric long-distance reflexive may require mood changes; thus Icelandic long-distance reflexives mostly require a subjunctive clause (but see Hellan, 1988: 89 and references therein). But the general optionality of logophoric pronouns and longdistance anaphors is fairly clear if unhighlighted in the literature (see Anderson, 1986: 66 re Icelandic; Everaert, 1982: 2 re Dutch; Stirling, 1988: $247 \mathrm{f}$. re the African languages).

[21] For example, Icelandic permits only non-nominative subject anaphors (Everaert, 1986: $172,302 \mathrm{ff}$.), although this seems to be nothing more than a morphological gap as shown by the possibility of oblique case reflexive subjects (Anderson, 1986: 69 f.). 
'logophoric' contexts, namely reported speech events, these perspectival centres coincide on one individual, but in other contexts (like complements of 'psych-verbs') only one or two of these perspectives may be involved (Sells, 1987: 456). In the African languages which gave rise to the original 'logophoric' analysis (Hagège, 1974), in a prototypical logophoric context which might, e.g. be glossed as Bill said he would come, co-reference together with the coincidence of subjective perspectives is encoded (often) by a special pronoun. In the case of long-distance reflexives, like Japanese zibun, we seem to be dealing with looser requirements. For instance, according to Sells' analysis, zibun requires that the antecedent be the 'pivot' or centre to which deixis has been relativized, while antecedents of Icelandic long-range reflexives have to be a different kind of perspectival centre, namely the person from whose mental life the scene is viewed (the self). And so on. But although the details of the requirements that antecedents of long-range reflexives have to meet vary slightly from language to language, the essential point Sells establishes is that what is suggested by the use of the reflexive in such languages is a contrast with the ordinary, objective, 'deictic' point of view, that of an uninvolved observer.

Stirling (1988: ch. 6), while adopting Sells' treatment in terms of Discourse Representation Theory (DRT) of the conditions put on antecedents by logophoric predicates and pronouns, argues that Sells' tripartite decomposition of the relevant notions is over-elaborate: she instead argues that we only need to distinguish between the relativized deictic centre (Sells' pivot) and the VALIDATOR of the utterance, that is the person who vouches for the described situation. Where the validator is not the current speaker, but rather for example some reported speaker, we are dealing with a logophoric context. This account seems more in line with O'Connor's (1987) observation that logophoric items have collocational restrictions with evidentials. ${ }^{22}$

Here we must leave aside all these complexities both in the languagespecific distribution of long-range reflexives and the exact analysis of the semantic nuances involved. But this recurrent reporting of such a perspectival meaning difference between the use of a pronoun and the use of a reflexive is crucial to a pragmatic account of Binding, BECAUSE IT REVIVES THE POSSIBILITY OF A Q-IMPLICATURE CONTRAST BETWEEN PRONOUN AND REFLEXIVE EVEN WHERE THEY MAY BOTH OCCUR WITH THE SAME REFERENCE. For a Q-based contrast should be a contrast in informativeness, but not necessarily a contrast

[22] Stirling also treats the validator as a deictic discourse referent entered into the top level of a Discourse Representation Structure, in contrast to Sells' treatment of his three roles as predicated restrictions on discourse referents. This would seem to avoid a technical difficulty that Sells fails to see, namely that on his account the roles would fall under the scope of negation, incorrectly predicting that some sentence glossing as 'John didn't say that self would come' might mean that John said that he would come but 'he' was not logophoric! The point is that the proper treatment of 'presuppositional', background pragmatic conditions in DRT has not been properly thought through. 
in referential possibility. It will be sufficient for a pragmatic account that the use of the pronoun should invoke an interpretation that is less informative than that invoked by the reflexive. This line of reasoning has in fact already (and quite independently of my endeavours) been explored by O'Connor (1987). Considering the details of both long-range reflexives and switch reference in Northern Pomo, she came to the conclusion that disjoint reference is not encoded by either pronouns or 'switched reference' markers; rather, as we have claimed for disjoint reference generally, it is implicated (she appeals to Reinhart's account in terms of a Manner maxim, but we can assimilate the account to our Q-implicature). Noting the overlap in distribution between long-range reflexives and pronouns, she notes that if we take the reflexive to encode two meaning elements, co-reference and logophoricity, then the use of the pronoun will be warranted wherever the speaker wishes to avoid co-reference, logophoricity or both. In our terms we have a Q-contrast between the reflexive and the ordinary pronoun, schematically: ${ }^{23}$

$$
\begin{array}{ll}
\text { self } & h e / \text { she } / \text { it } \\
{\left[\begin{array}{l}
+ \text { logophoric } \\
+ \text { locally co-referential }
\end{array}\right]} & {\left[\begin{array}{l} 
\pm \text { logophoric } \\
\pm \text { referential dependency }
\end{array}\right]}
\end{array}
$$

Thus, we have a Horn-scale: 〈LONG-REFLEXIVE, PRONOUN〉, such that the use of the pronoun Q-implicates EITHER disjoint reference oR nonlogophoricity (or both). For example, take, in English gloss, the case of a language (like Japanese or Korean in (2I) and (22) above) that allows a nominative long-distance anaphor (here glossed 'self') to alternate with a nominative pronominal (here glossed 'he'):

(24) (a) John said that self lacked ability

(b) John said that he lacked ability

(24a) encodes both logophoricity (or protagonist's perspective) and necessary referential dependence (or co-reference); thus the use of the less informative (24b), unmarked for either referential dependency or logophoricity, implicates that the speaker wishes to avoid at least one of the features encoded by the reflexive. A co-referential interpretation for the ordinary pronoun in $(24 \mathrm{~b})$ is not therefore ruled out. If there is reason to think that the speaker wishes to avoid a logophoric interpretation, then that will be

[23] Compare Kuno's (1987: I41) conjunctive definition of the conditions under which Icelandic long-range reflexives can be used: 'A reflexive pronoun can be used in a complement clause in Icelandic if it is co-referential with a [+logo-I] NP of the main clause AND if the complement clause is an expression of the logophoric NP's point of view rather than the speaker's rendition of it ' (where the $[+\operatorname{logo-1}]$ feature marks the source of a reported speech event - e.g. John in John told Mary he'd come - or more generally the experiencer). The conjunctive conditions for usage of the reflexive have as corollary DISIUNCTIVE conditions for the co-operative use of the pronoun: use the pronoun when either or both of the conditions for the use of the reflexive do not obtain. 
sufficient reason for him to have avoided the reflexive. The Q-inference to non-logophoric viewpoint will then be consistent with the lower priority Iinference to co-reference, and both will go through. So now we have a Qcontrast that may or may not be a contrast in reference-hence the neutralization in reference (but not in overall meaning) in these positions. In contrast to such a pragmatic account, a GB theorist will be forced into positing different binding domains for pronouns and reflexives in order to account for their overlapping distribution. But experience shows that it is not easy to get such an account to work (Kuno, 1987). Chinese has been a test bed for theories of this sort (see Huang, 1983; Huang, I984; Battistella, I985; Iatridou, I986), but recent work by Y. Huang ( 1989 ) strongly suggests that a pragmatic account is inevitable.

If we now look back at Kuno's observations about English 'neutralizations' of this sort, it seems that O'Connor's conjecture might have application here too:

(25) English logophoricity (Kuno, 1987: I 20 ff.)

(a) According to John, it was written by Ann and himself

(b) ??Speaking of John, it was written by Ann and himself

If we take it that the long-range reflexive encodes a subjective point of view, then that would explain the oddity in $(25 \mathrm{~b})$ of the collocation of an alogophoric adverbial with a long range reflexive. O'Connor's conjecture thus reinvigorates the pragmatic account of Binding possibilities, explaining the apparent neutralizations between pronouns and reflexives that sometimes occur. But there is a difficulty for the pragmatic account that we have not faced up to. (It is a difficulty, I should add, for grammatical accounts too.) This is that the neutralization in reference between pronoun and reflexive, and the associated difference in logophoricity, only arises in certain locations. In English, one class of such locations are the peripheral adjuncts within the clause (as in away from him/himself in (18)); another class, more prominent in other languages, consists of the long-range reflexives. The residual problem for the pragmatic account thus comes down to this: why should the issue of logophoricity not arise in the contrast between reflexive and pronoun when these have core-argument clausemate antecedents? For many languages the same reflexive morpheme occurs in both clausemate and longrange contexts, as in the gloss below:

(26) (a) John hit self

(b) John hit $_{1}$ im $_{2}$

[a referential rather than a
logophoric contrast]

(c) John said self would come

(d) John $n_{1}$ said $h e_{1 / 2}$ would come

[a logophoric, not always

a referential, contrast]

But only in (26c) does the logophoric meaning seem to arise, just where the pronoun can routinely occur with the same reference. The question is thus 


\section{STEPHEN C. LEVINSON}

posed, on O'Connor's pragmatic account, why one can't say John hit him (or its equivalent in languages with logophoric reflexives) suggesting co-reference but an a-logophoric viewpoint. With clausemate antecedents the contrast always seems to be one of reference simpliciter, but with antecedents beyond the clause (or with an anaphor in an adjunct and the antecedent within the clause) the contrast between pronoun and reflexive can now be EITHER a contrast in reference $O R$ a contrast in logophoricity. One might claim, as Bouchard, Sells and others have, that true reflexives are restricted to the coreference between core-argument clausemates, the rest being merely homophonous contrastive pronouns of a special sort. ${ }^{24}$ But then we need an explanation for the cross-linguistic tendency for such homophony. Alternatively, one might seek for a further pragmatic factor that explains the over-riding concern with reference within the clause. This is the direction we shall now explore.

\subsection{Conclusions re the 'A-first' pragmatic analysis}

The A-first account is, I think, still a perfectly viable account of disjoint reference preferences in most languages which exhibit grammaticalized Anaphors. There are areas where it no doubt requires further exploration, as for example in the possibility of replacing Reinhart's configurational account of the disjointness of a pronoun c-commanding a lexical NP with an elaborated version of Bolinger's approach making use of theme/rheme distinctions. There are also areas where the account can be extended to deal with other related phenomena, as argued by O'Connor: for example, the indication of disjoint reference by switch reference systems may be implicated rather than coded, and the contrast between pronoun and long-range reflexive may consist in a Q-implicature from the use of the pronoun to the effect that EITHER reference is disjoint oR the perspective is non-logophoric. Nonetheless, there remain some difficulties. The first is that the A-first account will obviously fail to say anything at all about anaphora in languages that lack coded Anaphors. The second is that, as just reviewed, there seems to be a need for an independent explanation of the strong presumption of disjointness within the clause: such that in this location, a pronoun always Q-implicates disjoint reference with a clausemate antecedent rather than a-logophoricity.

\section{THE 'B-FIRST' ACCOUNT: PRAGMATIC REDUCTION OF BINDING CONDITIONS A AND C}

I now want to explore a radical alternative to the preceding account which, it will be recalled, accepted Principle A of the Binding Conditions as a basic

[24] See for instance Bouchard, 1983. 
rule of grammar, and developed pragmatic reductions of Principles $\mathrm{B}$ and $\mathrm{C}$ as parasitic on $A$. In this alternative, we shift the centre of the account and make the Principle B pattern basic and treat Principle A and Principle $\mathrm{C}$ as pragmatic derivatives. I believe that such an alternative account may be attractive for some languages at certain points in their history; and since the account uses the same pragmatic apparatus I see no theoretical inconsistency between what I shall call the 'A-first' and the 'B-first' accounts. Rather, any one language (now being thought of as a sociolinguistic entity) should be treated as having stabilized a particular pattern of anaphoric interpretation as basic, as the conceptual anchorage for the rest of the system. This stabilized core (whether Principle A-like or Principle B-like) is then subject to our familiar $Q, I$ and $M$ inferences, yielding 'for free' the rest of the system. All this amounts to a kind of parameterization of the pragmatics of anaphora; as on a GB account the language learner will find the relevant values of the parameter from the environment, but unlike GB the range of parametric variation would seem to derive from alternative applications of the same pragmatic principles, rather than from innate linguistic constraints. Later I will argue that in fact A-first languages tend to exhibit residues of a B-first stage, thus showing that there is no radical discontinuity between these types.

Here is how a B-first account might be developed. First we take it that we have a stabilized pattern of interpretation where clausemate NPs are preferentially interpreted as distinct in reference. This could be thought of as a matter of grammatical stipulation, Principle B surfacing as part of Universal Grammar. But it need not be - and this is one of the attractions of the B-first account - for the core pattern could itself be pragmatically motivated. Farmer and Harnish (1987), for example, have advanced this as the basic datum for pronominal anaphora: they propose a pragmatic 'Disjoint Reference Presumption', namely that 'the arguments of a predicate are intended to be disjoint, unless marked otherwise' (1987: 557). The origin of such a pragmatic presumption is left unclear on their account, but we may perhaps be able to relate it to our Generalized Conversational Implicatures framework. For it would seem to be a matter of inductive fact that agents normally act upon entities other than themselves; the prototypical action - what is described by the prototypical transitive clause - is one agent acting upon some entity distinct from itself. If that is how the world stereotypically is, then an interpretation of an arbitrary transitive sentence as having referentially distinct arguments is given to us by the I-principle, which encourages and warrants an interpretation to the stereotype. ${ }^{25}$

[25] 'Bite' took this paragraph to be advocating a radical behaviourism: the language of transitive clauses, inductively learnt, mirrors the world of causal events. That is not the point being advocated. The I-principle is a principle of default interpretation, which capitalizes on the under-specification of linguistic meaning together with the mutual knowledge of inductive regularities in the world, to yield rich interpretations as hypotheses 
Perhaps the derivation of the preference for disjoint arguments of a single clause is not so simple. Why shouldn't the Piagetian egocentric child arrive at the contrary presumption, that prototypical events (like scratching oneself) involve the agent acting on itself? And what if the inductive facts are out of line with our stereotypes (as in Putnam's example of the stereotypical ferocity of the gorilla)? And if the non-reflexive stereotypical relation is sufficient explanation for the markedness of the reflexive relation, what else is going to explain why languages always opt for marking the object rather than the subject (*heself hit John)? The queries can be answered in fairly obvious ways, but they do perhaps point to the need for a theory of stereotypes and their inductive basis rather than a rhetorical gesture. ${ }^{26}$

But whether we take the Principle B-like pattern itself to be given pragmatically or not, we can then derive the Principle A pattern this way. First note that reflexives and other Anaphors are MARKED forms; if they are pronoun-like in grammatical category they tend to be longer, more morphologically complex than ordinary pronouns (compare himself with him); if reflexivity is encoded on the verb (as arguably in Australian antipassives), then the verbal morphology is marked. Thus, what the marked, prolix forms indicate is that the normal, stereotypical scenario associated with a transitive clause does not in fact obtain - notice is served by $\mathrm{M}$ implicature that the I-inference to the stereotype is not intended. If the stereotype is disjoint reference for arguments, then the M-implicature is (by Horn's (1985) division of pragmatic labour) to the complement of that interpretation, that is to co-reference. Hence (given that, by our projection rules for implicatures, $\mathrm{M}$-implicatures cancel any rival I-implicatures) we

about utterance-meaning. Like most pragmatic theories (certainly of the Gricean sort), the pragmatic apparatus is presumed to be parasitic on an independent syntax, and on an at least partially independent semantics (in this instance, of transitive clauses). What is at stake here is whether, in the B-first languages shortly to be described, disjoint reference of clausemate NPs is given by some principle (such as Binding Principle B) of Universal Grammar, or whether disjoint/conjoint reference is part of the underspecification of linguistic meaning just mentioned, to be resolved at a pragmatic level. I entertain the latter hypothesis, for the reason, to be illustrated below, that otherwise co-reference of clausemate NPs in languages without Anaphors would be (incorrectly) predicted to be impossible.

[26] My thanks to the same gadfly reviewer 'Bite', who remarked 'it is typical of the functionalist perspective to be rather blasé about its radical innatist tendencies while taking more serious proposals to task'. He or she also raised the issue of Exceptional Casemarking ('Subject-to-Object Raising' or 'S-Bar deleting') contexts as in: John $n_{1}$ revealed himself $/$ him $_{2}$ to be a Mason, where him must belong to the lower clause, so could not be subject to our pragmatic preference for disjoint reference, so cannot be a context where the reflexive can be accounted for as marking the complementary interpretation. The response is that were these contexts to be the central uses of reflexives then our theory would collapse. But of course they are not; they are even absent from (or exist only in residual forms in) closely related languages like German (Hawkins, 1986: 77). They do of course convincingly show that there are syntactic rules for the use of the reflexive in English - but that is not in question. What is in question is whether there is functional motivation for the central pattern. 
derive the Principle A-like pattern for marked pronouns, so called 'Anaphors'. It remains to account for the Principle C-like pattern. Here the account is familiar: where a pronoun is not a clausemate with another NP (thus the pragmatic Principle B-like pattern is not in play), there will be nothing to prevent the I-implicated tendency to co-reference (assuming matched agreement features, etc.). But if, just where such a pronoun would so implicate co-reference, a marked form (in this case a lexical referring expression) is employed instead, then again we get the complementary interpretation, this time to disjoint reference.

Thus, to recapitulate: sentence (27a) is interpreted with disjoint arguments in line with the (I-induced) stereotype 'clausemate arguments are distinct'; the marked form of the pronoun in (27b) warns (M-implicates) 'contrary to stereotype', and since M-implicatures over-ride I-implicatures, we obtain a conjoint interpretation; the pronoun in $(27 \mathrm{c})$ on the other hand does not fall under the presumption of clausemate disjointness since the only potential antecedent is in another clause; the pronoun is unmarked, so there is nothing to stop the I-preference for co-referentiality of reduced forms going through; while in $(27 \mathrm{~d})$, by contrast, the use of a full lexical NP suggests (Mimplicates) that whatever might have been implicated by the use of the pronoun is being avoided, and thus that the complement of the interpretation in $(27 \mathrm{c})$ (now disjointness) is intended.

\section{(27) (a) John likes him}

(b) John likes him-self

(c) John said he went

(d) John said the boy went [disjoint by I or other clausemate disjointness presumption] [conjoint by $\mathrm{M}$ ] [conjoint by I] [disjoint by $\mathrm{M}$ ]

There is rather a lot of evidence of different kinds in favour of a B-first pragmatic analysis of this kind for at least certain languages. One form of support comes from typological evidence for a widespread association of reflexives and emphatics; in language after language, the reflexive seems to be homophonous with an emphatic particle or affix (Moravcsik, 1972; Langacker \& Munro, 1975). ${ }^{27}$ For example, just as in English we have the

[27] The term 'emphatic' is (as Faltz, 1985: 239 remarks) regrettably vague. Without attempting any careful analysis, we may note though that what we have in mind are, for example, the various uses of the English 'reflexive' as illustrated in:

(i) The Queen herself said so

(ii) He cut the lawn himself

(iii) He flogged the Bishop himself

The effect in these cases may be glossed 'and not anyone else', 'not through the agency of a third party', etc. The effect is thus to insist on the exact reference, to rebut a contrary suggestion or a stereotypical presumption, etc. The scope of such particles can be complex, as indicated by the ambiguity of the last example ('He himself flogged the Bishop' vs. 'The Bishop himself was flogged by him'). For a useful exploration of the semantics/pragmatics and scope of such particles, see König, 1991. He notes that a 'general phenomenon is 
emphatic use in (28a) of the 'reflexive' as in (28b), so for example in Tamil we have the emphatic particle in $(28 \mathrm{c})$ homophonous with the root of the reflexive pronoun in $(28 \mathrm{~d})$.

(28) (a) The Prime Minister herself will come.

(b) She hit herself

(c) Ava-taan varuva

She-EMPH will come

(d) Ava taan-e aTicca

She self-ACC hit

The B-first account predicts this; on such a view, anaphors are just pronouns marked in such a way that they will trigger an $\mathbf{M}$-implicature to the complement of the normal interpretation; if clausemates are normally disjoint, a marked pronoun will $\mathrm{M}$-implicate co-reference. The contrastive, emphatic particle or affix will do the job nicely. ${ }^{28}$

the fact that scalar additive particles often take the same form as the so-called emphatic reflexive pronouns or 'intensifiers': G. selbst, D. zelf, Norw. Selv, Fr. même, Ir. fein. ' (MS, 233). Thus he relates scalar even to the emphatic uses of himself (cf. French même, German selbst cognate with English self) - both, to follow Edmondson \& Plank (1978), 'associate a pragmatic scale with propositions graduated in terms of the speaker's expectations of the involvement of certain individuals in the relevant states, process and events' (MS, 235). See also Kay, 1987.

[28] One difficulty with this line of explanation, Bite suggests, is raised by the Germanic languages, which typically have two reflexive forms, cognate with German 'weak reflexive' sich (associated with inherently reflexive verbs) and 'strong reflexive' sich selbst. Contrary to what one might expect given the argument, it is the weak reflexives that participate in long distance binding and its associated logophoricity (see for instance Everaert, 1986: 2 I 2 f.; Hellan, I988: $87 \mathrm{ff}$., 95; for this reason the inorphologically unmarked 'weak' reflexives are sometimes called, from a Binding perspective, 'marked'). On the other hand, the strong reflexives have not had the same intensive study as the weak ones (Hellan, I988: 87), so perhaps the facts are not so clear; for example, the strong reflexives in Dutch, Norwegian and Icelandic also have long range uses if they are stressed (Everaert, 1986: 218 f.; 253 fn. 4; 254 fn. 12; Hellan, 1986: 104), an observation in line with the current theory. But clearly the main factor here is the relative antiquity of the weak reflexive (from proto-Indo-European * $s(w)$-, lost from West Germanic then reborrowed later in Dutch for example), which may itself derive from an emphatic (see Section 4 below). The strong reflexive form in all these languages seems to retain the pure emphatic functions (for example as a modifier of a subject) and to be in the process of extending its functions in the way predicted by the argument here. For some generalizations about 'weak'/' marked' vs. 'strong'/" unmarked ' reflexives, see Faltz, 1985; Yang, 1983. For an attempt to predict their respective distributions see Pica, I984, 1987; Everaert, 1986: ch. 8. Rizzi (1989) treats the association of weak (morphologically simple) reflexives and long-range binding (and conversely, compound reflexives and local binding) as so universally strong that it would suffice for 'Degree-o learnability' - a child would not even need access to subordinate clauses to know what the binding domain of a specific lexical Anaphor was! But Chinese for example allows long reflexivization with both simple ziji and compound ta ziji (Y. Huang, 1989: 96). The tendency for 'weak' (morphologically simpler) reflexives to have long distance uses is attributed by Faltz (1985: $256 \mathrm{ff}$.) to their diachronic origins as stressed pronouns in subordinate clauses, as with the African logophoric pronouns and perhaps proto-Indo-European ' $s(w)$-. If the association between 'weak' reflexives and long-range uses does turn out to be a language-family wide generalization, there is a direct 
What is being offered here is, of course, a very simple, and no doubt in part simplistic, explanation for the oft-noted overlap between reflexive and emphatic forms. That overlap is sufficiently salient that there have been a number of attempts to try and explain it. In the heyday of Generative Semantics there were attempts for example to derive John himself came from John, he came (Moyne, I97I) or John-John's own self-came (Cantrall, 1973). There have also been careful and interesting attempts to characterize the exact semantic/pragmatic import of the intensifier use of reflexive forms. Thus Moravcsik ( I 972) distinguished a 'head-bound' use (as in John himself came) from an adverbial use (John came himself), and Edmondson and Plank (1978) suggest the first has to do with a pragmatic scale (in the sense of Fauconnier, 1975) of unexpectedness, the second with a scale of direct agency or experience. ${ }^{29}$ Philosophers, too, have speculated on the meaning of phrases like $\mathrm{He}$ himself. Hintikka (1970) for example claiming that the intensifier rules out an intensional (or attributive) interpretation, Geach (1972) that it translates a first person pronoun into a form appropriate for indirect speech (see the discussion of logophoricity above). All of this is usefully reviewed in Edmondson \& Plank, I978 and König, I99I, but summarizing the semantico-pragmatic effects of the intensifier uses of reflexive forms, we may note that (a) there is a contrastive, contrary-toexpectation element; (b) there is a natural negative gloss, of the sort 'and not anyone else', 'and not the more expectable persons'; (c) the intensifier often plays a role in reference, by forcing a particular co-referential interpretation of a pronoun $;^{30}$ (d) the intensifier could often be replaced with like effect by stress; (e) issues of scope arise according to placement. All of these features are compatible with, indeed explained by, an account in terms of $\mathbf{M}$ implicature and Horn's (1985) 'division of pragmatic labour' (that is to say, in my terms, the complementarity of I-implicatures and M-implicatures). $\mathrm{M}$ -

potential explanation from our theory. The very fact that clausemate reflexivity is indicated only by an emphatic form, which in long-range uses may be indicating merely a contrast in perspective rather than reference, may motivate double-emphasis in the clausemate cases. In fact there is direct diachronic evidence for this process in the origin of many 'strong' reflexive forms as double or triple emphatics: for example, Homeric Greek reflexive he- (from Proto-Indo-European ${ }^{*} s(w)$-) was later fused with autós (a form used like English -self to form compound reflexives) to yield Classical heauton in the third person, this in turn becoming Modern eaftós, now further modified with a possessive pronoun indicating person, as in eaftó $t u$, 'self his'. Proto-Romance *met-ipsimum is an even clearer case of triple emphatic derivation - see footnote 47 .

[29] Edmondson \& Plank ( $1978: 386$ ) in fact suggest that there is third himself in English which indicates a reversal of semantic roles, as in Bill hit Sue and was himself hit by Ann.

[30] For example, after Edmondson \& Plank, 1978: 380: 'John is a hippy. John's brother is a banker, happily married with three children. He/He himself/HE is very much admired by people of his own type.' The tendency is to take the unadorned pronoun to refer locally to John's brother (as predicted by the I-principle), but a marked pronoun (with the intensifier himself or intonational/stress prominence) suggests co-reference with John (by 'Horn's division of labour' whereby a marked form M-implicates the complement of the I-implicature that would have arisen from the unmarked form). 
implicatures, by picking out the complementary interpretation to the stereotypical I-based interpretation that would have been generated by the use of a simple unmarked form, naturally give rise to contrary-to-stereotype, negative interpretations. It is left open on this account that the contrast intended may be either one of unexpectedness or point of view, on the one hand, or one of reference, on the other. That contrastive stress might do exactly the same job is likewise explained - for all the intensification of the NP is doing is warning of a marked interpretation. Finally, the fact that issues of scope arise in no way demonstrates a codified semantic base for all these meanings - for such issues also arise with classic implicatures, giving rise to a complex projection problem for implicatures (Levinson, in prep., ch. 2). Thus simple though it is, the B-first account of the overlap between reflexive pronouns and emphatic intensifiers modifying pronouns has much to recommend it.

There is more general evidence for the use of marked forms to indicate marked, reflexive, interpretations. In those languages, like many Australian ones, where the reflexive is signalled by a special verb form, that verb form is a marked form. In languages like Guugu Yimidhirr (Haviland, I979; Levinson, $1987 \mathrm{a}, \mathrm{b})$ this special verb-form does not directly encode reflexivity, but only indicates directly that one argument is missing. There is a pragmatic inference in many cases to the reflexive. But this can be further reinforced by the use of an emphatic affix which then makes the reflexive or reciprocal reading central:

\section{(29) bama-gu gunda-dhi \\ the people (ABS)-EMPH hit-ANTIPASSIVE \\ 'the people hit each other' \\ or 'the people hit themselves' \\ or 'someone hit the people'}

Thus in languages which currently lack, but which seem to be in the process of acquiring, fully grammaticalized, unequivocal anaphors, we can find the same association between markedness and reflexive readings.

A third closely related kind of evidence for the B-first account is the diachronic fact that reflexives seem in many cases to have derived from emphatic or contrastive forms, even if there is no longer a homophonous corresponding emphatic particle or affix. Such appears to be the case with Tamil taan, or Chinese, ziji, for example, and I will discuss the history of English reflexives below in detail. However, the most persuasive kind of evidence for the B-first analysis comes from consideration of languages that lack Anaphors altogether. As we've noted, such languages obviously cannot support an A-first analysis. It is therefore crucial to see what patterns of anaphora they exhibit. 


\section{I. Languages without reflexives}

There are scattered reports from around the world of languages that do not directly code reflexivity. Such languages seem to have been largely ignored by grammatical theorists even though they would appear to be crucial evidence against the centrality of the Binding apparatus. ${ }^{31}$ It is not yet clear just how common the absence of reflexives is. Faltz (I977: 2 Io f.) cites the Low West Germanic sub-group of languages (including Old English) and Biblical Hebrew; Carden and Stewart (1986: 51) cite Fijian and other Austronesian languages, ${ }^{32}$ a non-Austronesian New Guinea language Haruai (data from Comrie), and about half the pidgins and creoles (in many cases by independent innovation). We can add many Australian languages, and there are no doubt other groups of languages yet to be reported. In this section I provide a sketch of the facts for some of these cases to aid and abet the rehabilitation of these linguistic orphans.

3.I.I. Australian languages. We have already seen that there are languages, like Guugu Yimidhirr, which lack true reflexives. In fact, the majority of Australian languages would seem to lack Anaphors. Instead, in many of these languages the reflexive meaning is indicated by a semantically general anti-passive or detransitivized clause (Dixon, 1980: 448). The anti-passive construction can be thought of as transforming a transitive clause into an intransitive one with a single Absolutive argument; it thus simply indicates that, for one reason or another, one of the arguments of the verb is missing, unknown or irrelevant. The reflexive meaning is just one natural interpretation of the anti-passive; but as we noted for Guugu Yimidhirr, the reflexive interpretation can be forced by an emphatic affix on the sole argument (as we would expect on the B-first account, which derives reflexives from marked pronouns, or more generally, marked reflexive clauses from unmarked non-reflexive ones). In some languages, though, the use of such an intransitive form to express 'reflexive meaning' is optional. For example Dixon (1983:497) reports on Nyawaygi, where the reflexive can be expressed by an anti-passive, a regular transitive with two ordinary NPs (one in the

[31] An anonymous referee comments that the existence of languages without Anaphors is no more embarrassing to GB than the existence of languages without nasal consonants, although it might be interesting to see whether such languages invariably fail to have NP movement processes, as GB-theory might predict. Such a correlation is almost certainly missing; for example, one can find passives in most of the languages under consideration. There is in fact one detailed GB-style analysis of a B-first language which has come to my attention late in the preparation of this paper. Chung (1989) describes Chamorro as without surface Anaphors but with canonical NP-traces in Raising and Passive constructions. Chung in fact is driven to the reluctant conclusion that Chomsky's parallel between movement and bound-anaphora may have to be abandoned. See the discussion below.

[32] See for example Tryon (1970: 97) on Tahitian. 
Ergative and the other in the Absolutive case), or a transitive verb with two NPs in the Absolutive case. In other languages one simply has two NPs in the Absolutive with a normal transitive verb, as if they were both the subjects (one the head, the other a modifying adjunct) of an intransitive verb. Again, this seems to be optional; in Wargamay one can express 'I've cut my foot' in two ways (Dixon, $198 \mathrm{r}: 64-65$ ):

(30) (a) ngayba bingany gunbay

ISG-S foot-ABS cut-UNMKD

'I-foot cut'

(b) ngaDa gunbay bingany ngaygu

ISG-A cut-UNMKD foot-ABS ISG-GEN

'I cut my foot.'

And recollect the Guugu Yimidhirr facts above. There is no unequivocal reflexive or reciprocal construction. To indicate reflexivity one uses a detransitivizing verbal affix, thus suggesting the irrelevance of the missing argument. That irrelevance may stem from the speaker's not knowing who or what the agent was, or from the accidental nature of the agency (for instance, the wind blowing something over), or from the fact that the missing argument is identical to the surviving one. However, the reflexive reading can be made prominent by marking the surviving NP with the emphatic particle $-: g u$ as we noted. The same use of the emphatic attached to a pronoun can suggest co-referentiality where the anti-passive construction cannot be used, as in a sentence with the meaning ' John ${ }_{1}$ helped his $_{1}$-EMPHATIC father'. Here we see an emphatic reflexive in the very making.

However, some of these languages do not employ any such device at all. For example, in Gumbaynggir (New South Wales) the reflexive is expressed by a normal transitive sentence (Eades, 1979: 3I2):

(3I) gua:du bu:rwang gula:na magayu

3SG-ERG paint-PAST 3SG-ABS red paint-INST

$\mathrm{He}_{1}$ painted him $_{1 / 2}$ with red paint

'He painted himself/him with red paint.'

There would appear to be a suffix - $w$ (gula:naw instead of gula:na above) that forces a reflexive reading, but this is definitely optional (p. 313). Similarly, Peter Austin (1987) reports that Jiwarli does not formally express any distinction between an ordinary transitive sentence and a reflexive meaning: 'Jiwarli reflexives are indistinguishable from simple transitive clauses except that the subject and object nominals are co-referential', thus:

(32) Nhurra-lu puthirninyja nhurra-nha

You-ERG hit-PAST you-ACC

'You hit you' (= 'You hit yourself') 
3.1.2. Austronesian: Fijian. A number of Austronesian languages are reported to lack reflexives and reciprocals, but Fijian is perhaps the best documented. In Dixon's (1988: 255-256) grammar we find that 'For first and second persons the reflexive is simply shown by using the appropriate pronoun in both subject and object slots'; or, if it is an indirect object that is involved, the ordinary pronoun in the relevant case is used. In the third person, a verb with the transitive marker $-a$ and without an explicit object will be interpreted as having 'unmarked reference to a 3 sg object' which is non-co-referential with the subject. If co-reference or reflexivity is intended, a full object pronoun (e.g. 'ea, 3sg Object) is required, and although this might be interpreted disjointly, it encourages a co-referential reading:

(33) sa va'a-.dodonu-.ta'ini 'ea
ASP correct
'Mike corrected himself' or
'Mike corrected him'

The pattern looks like our hypothesized B-first type: the least marked form of a transitive clause encourages the supposition that the arguments are distinct in reference; any marked form raises some possible doubt about this, and so is the normal way to express co-reference if intended. Apparently the same holds for the expression of the reciprocal relationship, although there are also intransitive roots and so on that can also be used to express this. ${ }^{33}$

An Austronesian language that has been the subject of some detailed GB work is Chamorro (Chung, 1989). Chung notes (1989: I48 ff.) that Anaphors and Pronominals are morphologically identical just as in Fijian, although the reflexive interpretation can be forced by an optional adverb maisa (glossed as 'by oneself'). However, she goes on to argue that two grammatical constraints are sensitive to the coindexing of NPs within minimal governing categories, and therefore that Chamorro quasi-pronominals are in effect ambiguous ('morphologically syncretic'), distinguished into Anaphors and Pronominals at the syntactic level. A peculiar consequence, however, of taking these constraints to be syntactic criteria for covert Anaphors is that the same criteria then identify NP-trace and PRO as non-Anaphors ( $173 \mathrm{ff}$.). It seems to me then that it may be preferable to treat the special constraints on Chamorro pronominals construed reflexively as semantic. For example, there seems to be a syntactic filter banning any third-person plural subject of a normal transitive clause, UNLESS subject and object are co-referential. But

[33] Another Austronesian language, Tahitian, apparently follows the same sort of pattern (Tryon, 1970: 97). To express the reflexive one can only use the pronoun:

(i) 'ua ha'opohe 'oia 'iana was kill he him 'He killed himself'

But there is an emphatic affix iho, which when added to the pronoun seems to be the standard way to express at least the reciprocal meaning. 
the exception is surely based on the natural semantic conception of reflexive clauses as quasi-intransitive, as shown in the world-wide association of middle verb-forms with reflexivity both synchronically and diachronically (see Genuišienè, 1987). The second constraint likewise gives no real support to a syntactic distinction between Anaphor and Pronominal. In any case, Chamorro is clearly a language where a single range of pronominals does double duty as a set of reflexive and non-reflexive pronouns, as seems often to be the case in the Austronesian family. ${ }^{34}$

\section{I.3. Creoles.$^{35} \mathrm{~A}$ third and diverse group of languages that seem generally} to lack Anaphors are the pidgins and creoles of all origins. These languages have recently been surveyed by Carden and Stewart (I986, I987, I988) to see to what extent the Binding Conditions adequately describe their anaphoric patterns. They point out that the issue is rather interesting from the point of view of the 'bio-program' hypothesis advanced by Bickerton (1981). If the Binding Conditions are innate, and if pidgins upon creolizing should reveal the essential stripped-down properties of human language, then we might expect to find the Binding Conditions rapidly instantiated upon creolization. This is not however at all what was found in the survey. Instead, the evidence seems to show both that pidgins and creoles tend to lack Anaphors, and that they tend to lack a grammaticalized Binding Condition B (pronouns obligatorily disjoint with clausemate antecedents). I repeat a selection of their findings.

Carden and Stewart (1986: i3 f.) report that in the Northern dialect of Haitian creole the ordinary pronouns may be used as reflexives:

(34) (a) Emile dwe ede li

Emile should help him

(Emile can be co-referential with li)

(b) Emile dwe ede tèt-a-li (or kò-a-li)

Emile should help himself

(Emile and tèt-a-li must be co-referential)

[34] The other syntactic reflex of the supposed Anaphors in Chamorro is a 'subject effect' whereby co-reference is exceptionally ruled out where an antecedent precedes a pronominal subject (in general Chamorro seems to allow co-reference wherever an antecedent precedes or c-commands a pronominal). Since Chamorro pronominals are ambiguous on Chung's account, between Anaphors and Pronominals, it is not clear how such co-reference could be ruled out: an Anaphor and Pronominal in complementary distribution might be expected to cover all possibilities. Chung (1989: 162-I64) therefore argues that this disjointness is due to a pragmatic opposition of the kind used by Reinhart (1983) or in our Q-based account of A-first languages, preferring the use of the Anaphor (with a passive or active transform if necessary). If on the other hand no such distinction between Anaphors and Pronominals exists in Chamorro, then the constraint (syntactic, semantic or pragmatic) can be simply and directly expressed (whatever exactly its motivation).

[35] I am most grateful to David Perlmutter for putting me in touch with this work on creoles, not to mention useful discussions with him, conducted partly on the jog. 


\section{REDUCTION OF BINDING CONDITIONS}

They note that the literal meanings of tèt ('head') and $k \dot{o}$ ('body') play a role in the choice between these reflexive forms and that $t e ̀ t$ is used as an emphatic focusing particle as in tèt-Emile ('it was Emile himself'). They conclude from this that the Northern dialect of the creole can be treated as an earlier, less grammaticalized stage of the creole. Historical data seem to support this: the earliest materials provide plenty of evidence for the use of the plain pronouns as reflexives but little or no evidence for the specialized reflexive forms (I986: 20). The implication is that the earliest forms of the creole had no reflexives; the later reflexives based on body-part metaphors may be due either to ultimate (African) substrate sources or, just as likely, to independent invention. Other creoles also exhibit no reflexive forms, as for example the Spanish-based Palenquero (1986: 24), and perhaps half of all Creole lects allow the reflexive use of clausemate pronouns (Carden \& Stewart, 1986: footnote 58; 1987: $23 \mathrm{ff}$ - examples include Martinique Creole, Chinook Jargon, Bislama, KiNubi and Negerhollands). Corne (I988) shows that Mauritian Creole uses the ordinary pronouns as reflexives in the unmarked case, even though it has reflexive forms. (Although Corne believes this use of pronouns to be a post-creole innovation, Carden and Stewart (1989) reanalyze the historical material to argue that this use of the pronouns is derived from the original pidginization process.)

Comparison leads Carden and Stewart to hypothesize a diachronic sequence in creole languages (I here generalize from their discussion of Haitian creole, p. 26, in line with their footnote 58):

(i) STAGE I : no encoded reflexives; plain pronouns used reflexively.

(ii) STAGE 2: gradual emergence of morphological reflexives (based for example on body-part metaphors) with a clause-mate, subjectantecedent condition, co-existing with but encroaching upon the use of ordinary pronouns as reflexives.

(iii) STAGE 3: the loss of the reflexive use of the ordinary pronouns.

One point that they draw special attention to is that the tolerant treatment of pronouns as possible reflexives is not a feature that is by any means lost abruptly (surviving some hundreds of years in some dialects of the Haitian Creole), as might be expected if Principle B were part of the bioprogram that would assert itself immediately upon the acquisition of native speakers, in other words upon creolization of the original pidgin. The gradual nature of the change towards a typologically unmarked system (with reflexives and Principle B) argues either against Bickerton's idea that creolization should reveal the bioprogram in the raw as it were, or against the idea that the Binding Principles are core elements of that bioprogram. They also draw attention to the parallels in language acquisition. Studies by Solan (1987), Jakubowicz (1984) and others show that while the clausemate restriction on the interpretation of reflexives (in languages that have them) is acquired early, the Principle B non-reflexive use of pronouns is much more uncertainly 
acquired, with sometimes as many as $50 \%$ of four to six-year-olds finding a clausemate co-reference between an NP and a non-reflexive pronoun possible (Solan, 1987). As Carden and Stewart point out this finding is surprising in the light of the apparent rareness of languages that permit the reflexive use of ordinary clausemate pronouns.

In any case, the conclusion I wish to draw from the creole studies is that there is definite evidence in favour of a B-first analysis in such languages, both synchronically in that many creoles just use a marked or emphatic pronoun to indicate a reflexive, and diachronically in that creoles which do seem to have Anaphors also seem to have passed through a B-first stage with no Anaphors.

3.I.4. Old English. As the diachronic sequence hypothesized for creoles makes clear, a B-first analysis clearly projects a diachronic sequence: Anaphors should develop out of marked pronouns which are used to $\mathbf{M}$ implicate conjointness in opposition to the I-based presumption of disjoint clause-mates. In that case, an A-first language, at least one that codes reflexivity through reflexive pronouns, should develop out of a B-first language (at least that should be one likely source). English is then an interesting test case, because it was clearly at one stage, the earliest stage of Old English, a B-first language without encoded Anaphors.

According to Visser's (1963. Vol. I : 420-439) compendious treatment of Old English, self was not originally a reflexive element: 'in the earliest Old English texts self could be added to the personal pronouns in the nominative whenever this was thought necessary for the sake of emphasis... It seems however to have taken some time before self was added to the reflexive pronouns [i.e. ordinary pronouns used reflexively - SCL] ... that already from the beginning of the Old English period were widely used as objects without the addition of self' (ibid. 420). Thus, self clearly began as an emphatic adjectival adjunct to nominative pronouns 'with the purpose of emphasizing the identity of the person or thing denoted by the object and the subject' (ibid. 425), and at the time of Beowulf a reflexive object could only be expressed by the normal accusative pronouns, as in ic me clansie 'I washed me ${ }^{\prime} \cdot{ }^{36}$ By the time of King Alfred both that mode of expression and its counterpart with self (as in ic me selfne clansie) seem to have been current: thus both hie forseoo hie selfe and hie forseoo hie (ibid. 421). Indeed the use of the simple pronoun as a reflexive continued right through the Middle English period, although during that period (say I 200-I 500) 'there is a distinct change in the relative frequency of the two forms: the simple

[36] Mitchell (1985: 189) concurs with Visser's observation that 'emphatic self is found in the earliest texts in the nominative ... its use with an accusative reflexive pronoun appears to come later. It is not found in Beowulf, Genesis, Exodus, Christ and Satan, Deor or even Juliana, although it is evident in the prose of King Alfred's time'. 
pronouns, which in the beginning are numerically predominant, are gradually, and to an ever increasing extent, encroached upon by the compound pronouns ( $=$ pronouns + self $)$, with the result that by the second half of the fifteenth century they are more or less in the minority in most writings' (ibid. 432). Throughout this period then 'such a phrase as he ofsticode hine might mean either "he stabbed him" (someone else) or "he stabbed himself" (Visser, p. 433 citing Sweet). Visser suggests that the emphatic was increasingly used to avoid such possible ambiguities. ${ }^{37}$

It is tempting, of course, for modern commentators to make a sharp distinction between the emphatic and reflexive uses of self, "but to import it into OE is to follow a false native informant. As I see it Quirk and Wrenn are on the right track when they say... "For the most part, self was used in OE simply to emphasize and was not, as in Mod. E., associated with being a reflexive sign or a pronoun-enclitic"' (Mitchell, I985: I89). The essential fact about Old English is that both the plain pronoun, hine, and the corresponding emphatic pronoun, hine selfne, could be used either reflexively or non-reflexively in, for example, object position (Mitchell, I985: I I5) ${ }^{38}$ Thus the reflexive uses indubitably grew out of the emphatic uses, and not the other way around. Faltz $(1985: 242)$ notes a further piece of evidence for the evolution of reflexives from the use of emphatics to mark non-stereotypical interpretations. The hypothesis suggests that where a reflexive interpretation might in fact be stereotypical, as with predicates like 'wash' and 'dress', the emphatic pronouns would not in fact be used. And this seems to have been the case in Middle English: one said he cladde hym as a poure laborer rather than cladde hym self. The history of English thus seems to provide excellent evidence for an evolution of reflexives out of emphatics. The point at which the emphatic became grammaticalized as a reflexive can perhaps be equated with the point at which it lost its inflection, at the transition of Old to Middle English. But as just indicated, this long preceded the acquisition of Binding B-like patterns outlawing the reflexive use of ordinary pronouns, which survived well into Shakespeare and beyond (Visser, $1963: 435){ }^{39}$

[37] Visser (1963: 439 ff.) documents the same 'ambiguity' with the reciprocal meaning: $h i$ gecyston hi could mean either 'they kissed them' or 'they kissed each other', this usage surviving into Middle English, but being supplanted by various means of reciprocal marking, such as adverbs with this sense of 'mutually', and the each ... other forms already utilized in Old English.

[38] Mitchell (1985: 1 15) gives the following kind of example of the non-reflexive use of the form hine selfne:

(i) Moyses, se de was Gode sua weord dat he oft wio hine selfne sprac (from King Alfred's West Saxon version of Gregory's Pastoral Care 131.11)

On this example, see the discussion following (42) below.

[39] One additional element in this history that the historians of the language dwell on is the following progression : ic me clansie > ic me selfne clansie > ic clansie; that is, the loss of the reflexive object with verbs like wash, dress, shave, etc (see Jespersen, 1927: $325 \mathrm{f}$; Visser, 1963: $145 \mathrm{ff}$.). The correlation of the omission with the stereotypical reading (as predicted by the I-principle) is of course striking. 
However, regardless of the diachronic progression, there is little doubt that Old English was a classical B-first language, at least in the earliest period: it lacked Anaphors entirely, operating with a presumption of clausemate NP disjointness, a presumption that could be defeated by the use of a pronoun with an emphatic adjunct. The history of Dutch (and no doubt other West Germanic languages) might have been similar had it not been for the relatively recent influence of German: before then just as in Old English there were no reflexives, pronouns doing double duty ${ }^{40}$ But, according to Everaert (I986: 3), 'in the I4th and I5th centuries the eastern dialects of the Dutch language area started to use a sich-reflexive (which later developed into zich) under the influence of Middle Low German dialects involved in a process of sich adoption from Middle High German. If we look at the present-day nonstandard dialects we can observe that the use of zich is still limited to the eastern dialects (Ureland, $198 \mathrm{I}$ )'. Everaert notes that West Flemish (I986: 43 ) and Afrikaans (1986:39-40) continue to operate without morphological reflexives. ${ }^{41}$

There is no doubt, then, that there are languages without Anaphors or reflexives of any kind. The most interesting thing about such languages from the current point of view is that THE OPPOSITION BETWEEN CO-REFERENCE AND DISJOINT REFERENCE IN SUCH LANGUAGES CAN ONLY BE ACHIEVED PRAGMATICALLY; it can only be suggested, indeed implicated, by the choice of a specific kind of referring expression. If there are general pragmatic processes that can be reliably employed to make such referential distinctions in such languages (and there must be), then there is every reason to think that the same pragmatic processes operate in other languages to support partially grammaticalized oppositions of the same kind. Thus the very existence of languages of this sort is evidence in favour of the fundamental role that we are attributing to generalized conversational implicature in the interpretation of anaphora.

\subsection{Interim conclusions: the B-first account}

There is, then, distinct evidence in favour of a B-first analysis. First, as we have seen, there is evidence that there are languages that have no way of coding reflexivity at all. This makes an A-first analysis impossible of course; for the A-first analysis predicts all the patterns of anaphora as pragmatically derived from a grammatical core - something like Principle A of the Binding Conditions. It goes without saying that such B-first languages are even more serious challenges to the Chomskyan account (where Principle $A$ is claimed

[40] Thus, according to grammars of the seventeenth and eighteenth century, a sentence like $H i j$ beschuldight hem ('He accuses him/himself') was ambiguous. See Everaert, 1986: 3 ff. and references therein.

[41] A reflexive based on an emphatic, as in hem zelf, is also still current in standard Dutch, see Koster, 1986: $344 \mathrm{f}$. 
to have no basis in experience and is held to govern NP-movement as well as Anaphor construal). We can then ask whether in languages with an illdeveloped or zero coding of reflexivity, we can nevertheless find a grammaticalized Principle B. But the question suggests its own answer - if core-arguments of transitive verbs are necessarily disjoint, how could reflexivity be expressed at all in languages where there is no direct coding of it? So in such languages the assumption of disjoint clausemate arguments can only be a tendency: in short a pragmatic inference to the stereotype. What we do see in such languages is the acquisition of some device to suggest the non-stereotypical co-referential interpretation; the theory of Generalized Conversational Implicatures (GCI) predicts that such a device would be merely a matter of marking the NP or the verb as describing a marked situation, thereby $\mathrm{M}$-implicating conjoint reference against an I-based assumption of disjoint clausemates. Thus we obtain Principle A-like patterns of interpretation of marked pronouns as a pragmatic inference from a preestablished B-like pattern.

A B-first analysis therefore requires that Principle B-like patterns of interpretation cannot have a deep grammatical basis. Yet there is an intuition that the inference to disjoint reference in, say, John hit him is overwhelmingly strong. But of course the inference may only be that robust in the familiar languages blessed with Anaphors, where on an A-first account the inference is engendered (or reinforced) by a Q-contrast with the reflexive; and even there it may not be that strong (see the discussion under the rubric of defeasibility in Levinson, 1987 b). Further evidence for the relative weakness of B-like patterns comes from studies of child language acquisition. As mentioned, these studies (conducted on A-first languages like English) seem to show that children learning A-first languages learn the clausemate restriction on reflexives relatively early (as early as three) and relatively exceptionlessly (up to 95\%); but the assumption that a non-reflexive pronoun in object position is disjoint from the clausemate subject is learned relatively late (as late as five or six) and applied only some of the time (in some experimental conditions as little as $36 \%-$ see Solan, 1987; also Jakubowicz, 1984, Read \& Hare, 1979). All this fits the A-first analysis, which would make the Condition B-like patterns of interpretation a matter of Q-implicature. But it also indicates that Principle B is not as natural and robust as it seems to the intuitions of adult speakers of A-first languages.

We seem to be left then with the possibility that there are two rather radically different kinds of languages: those that have a grammaticalized Principle A (or similar), and those that lack it, but have a pragmatically based Principle B-like assumption that clausemate arguments are distinct unless otherwise indicated. The A-first languages are numerically in the ascendant, and there is historical evidence that the B-first languages tend to develop into A-first systems. In both cases, though, our theory of GCIs gives some account of how the rest of the anaphora patterns can be derived. 


\section{SYNTHESIS OF A-FIRST\& B-FIRST ACCOUNTS}

Let us sum up so far. We have reviewed the earlier A-first account of binding patterns, which makes the anaphoric patterns attributed by GB theorists to principles $\mathrm{B}$ and $\mathrm{C}$ of the Binding Conditions pragmatically derivative from grammaticalized Anaphors. We have shown how certain difficulties with this may be circumvented; and in particular we have shown that the most prominent problem, the overlap in distribution between (especially longrange) reflexives and pronouns, is not necessarily an overwhelming difficulty at all. Instead, by bringing the subtle 'logophoric' aspects of long-distance reflexives into the picture, we can maintain the Q-based contrast between pronoun and reflexive. Thus we end up with a natural extension of the A-first account into languages and phenomena (like switch-reference) beyond those for which it was originally developed. We can now say that there is a large class of languages (those we have been calling the A-first languages) that seem to fall within the scope of such a pragmatic reduction of the Binding Conditions.

One problem remains with the A-first account, sufficient to suggest that we are still missing an essential ingredient, namely the fact that the reflexive and the pronoun seem to be in a different kind of opposition when there is a potential antecedent within the clause compared to when the potential antecedent is outside the clause. In the first case, the opposition is nearly always one of reference; in the second case it is either one of reference or one of 'logophoricity', and hence the pronoun can often occur with the same reference. The different kinds of contrast that obtain in a language such as Chinese are represented schematically in (35):
(a) John hit self $_{1}$
(b) John 1 hit him
(c) John ${ }_{1}$ says that self $1_{1}$ will come
(d) John ${ }_{1}$ says that he $\mathrm{e}_{1 / 2}$ will come

[ \pm logophoric]

$\left[\begin{array}{l}\text { strongly disjoint } \\ \pm \text { logophoric }\end{array}\right]$

[+logophoric]

$\left[\begin{array}{l}\text { weakly disjoint } \\ - \text { logophoric }\end{array}\right]$

On the face of it, this fact in many languages with long-range reflexives predisposes us once again to a grammatical account, taking the reflexive and the pronoun to have different binding domains. However, once the wider facts about distribution of the reflexive are considered (like the fact that the antecedent can be far removed, even beyond the sentence, or deictically implicit), the grammatical account no longer looks tenable. The basic fact - a semantic fact - is that the reflexive is necessarily referentially dependent, the pronoun only optionally so; the search for an antecedent seems to be guided by matters of preferential interpretation, not grammatical principles (for an extended justification of this for Chinese, see Y. Huang, 1989). Besides, a grammatical account would leave the logophoric contrasts unaccounted for. 
If we bring our B-first analysis back into the consideration of our A-first languages, we can now find an answer to this rather central puzzle. Suppose we assume that in A-first languages we can find the same presumption that is central to the anaphoric operations of B-first languages, namely the presumption that core arguments of a single clause are disjoint. In addition, of course, we have the Q-implicated contrast between reflexive and pronoun, which in a language without long-distance reflexives is sufficient explanation for the tendency to read the pronoun as disjoint with a clausemate antecedent. It follows that in languages without long-distance reflexives, the presumption that core arguments are disjoint is redundant, which is why it never figured in our original A-first account. On the other hand, in languages with long-distance reflexives, although the two pragmatic principles will be largely overlapping and reinforcing, in the case of the longdistance use of the reflexive we will have a Q-contrast outside the scope of the clausemate-disjointness presumption. In those long-distance locations, the Q-contrast need not be interpreted as a contrast in reference (although it may be); it may instead be interpreted as a contrast in logophoricity, along the lines that O'Connor suggests.

To summarize the argument, then, we have two pragmatic principles at work:

(a) the presumption of clausemate core-argument disjointness, a stereotypical presumption that can be attributed to the I-principle;

(b) a scalar Q-implicature contrast between reflexive and pronoun, based on the differential semantic strength of the reflexive and the pronoun, the one being necessarily referentially dependent, the other only optionally so; the one suggesting emphasis and involvement, the other lacking such suggestions.

Where the two presumptions overlap, that is where antecedent and anaphoric items are core-argument clausemates, the first pragmatic presumption will ensure there is always a contrast in reference. The contrast in reference will be sufficient motivation for the choice between reflexive and pronoun, thus exhausting the pragmatic import. Outside these positions, a long-range reflexive is contrastive, but not necessarily contrastive in reference. Such a synchronic account goes some of the way towards answering our central puzzle, but it still leaves aspects of the puzzle unexplained. In particular, it is still not clear why the reflexive in long-range positions should have a logophoric interpretation that is not available in the clausemate use. Where does the deictic markedness come from?

The problem is only fully resolved, I believe, by taking a diachronic perspective, by looking at the anaphoric patterns that languages exhibit as accretions of pragmatic practices. We have already seen, in the review of the facts about creole languages, and more especially in the detailed facts about the history of Old English, some reason to believe that B-first systems evolve 
into A-first systems. I would now like to propose that this is the general evolutionary route by which the familiar A-first languages have arisen. Restricting ourselves to the languages that mark reflexivity by NP-type, on such a diachronic account, Anaphors arise as marked pronominal NPs Mimplicating contrast with the clausemate-disjointness presumption. But the use in a B-first language, as so often, of emphatics to encode the marking, is obviously consistent with a much wider use of such forms. In particular, since a deictic perspective is the perennial unmarked presumption, a marked or emphatic form may always suggest a contrastive perspective, one for instance where, as Stirling, 1988, puts it, the 'validator' is not the current speaker (see also Levinson, I988). Here we have the explanation of the association of 'logophoricity' with reflexives: both conjoint reference within the clause and a marked (non-)deictic perspective are perennial possibilities of interpretation of the use of a marked form in a B-first language, which will suggest by Mimplicature an interpretation complementary to the stereotypical one that would arise from the use of the corresponding unmarked form.

Putting these ingredients together, we may schematize the 'evolution' of reflexives and thus the diachronic progression from B-first languages to Afirst ones as follows : ${ }^{42}$

\section{Stage I: NO REFLEXIVES; CORE-ARGUMENTS TEND TO BE DISJOINT}

'John hit him' will I-implicate the stereotype 'core arguments are distinct in reference'; only ad hoc means such as the use of an emphatic to Mimplicate the complementary interpretation can be used to indicate coreference; the same means are likely to be used to $\mathrm{M}$-implicate a marked deictic perspective.

\section{Stage 2: EMPHATIC CORE-ARGUMENTS MAY BE CONJOINT}

The co-referential interpretation of 'John hit him' is now regularly reinforced by the use of a focus or 'emphatic' particle: 'John hit himEMPH' $M+>$ 'John hit himself'. An established usage of this sort reinforces: 'John hit him' $I+>$ 'John ${ }_{1}$ hit him ${ }_{2}$ '. But since the marking of pronouns is by a focus particle with general uses, other contrasts (beyond reference) may be intended; one such contrast being the point of view contrast called 'logophoric': 'John said he will come' expresses the

[42] The evolution in the other direction, by the loss of Anaphors, is not of course inconceivable; indeed this seems to be what exceptionally happened in the West Germanic languages which are presumed to have lost the reconstructed Proto-Germanic reflexive * sik (see below). But the diachronic processes here would be of a quite different kind, Nigel Vincent points out to me, perhaps due to phonetic change or language contact. The bidirectional possibilities should not be confused with some natural cycle; for example, Vincent (1989b) insists, the apparent synthesis-analysis-synthesis cycle in some Romance verbal inflections disguises quite different underlying mechanisms. The historical change of B-first to A-first systems would seem in accord with the kind of grammaticalization of analytic into synthetic grammatical systems. 
unmarked deictic point of view, while 'John said he-EMPH will come' $\mathrm{M}+>$ marked point of view.

\section{Stage 3: EMPHATICS BECOME REFLEXIVES (A-first system)}

An established system emerges: grammaticalized reflexives encoding necessary referential dependence within some domain. So now:

(a) co-core-argument positions: 'John hit him' is not only presumed disjoint by I, uncancelled by any $\mathrm{M}$-implicature, but also Q-implicates disjoint reference by the scale 〈Anaphor, Pronoun〉. Hence there is the strong inference to disjoint core-arguments from the use of a pronoun.

(b) where antecedent and anaphor are not clause-mate core-arguments: here the I-inference to disjointedness does not obtain. There is still a Q-contrast, but now a contrast in reference is not the only possible one, for the marked Anaphor may still carry the 'marked point of view' meaning (from Stage 2):

$$
\begin{array}{ll}
\text { 〈Reflexive, } & \text { Pronoun } \\
\text { + co-reference } & \text { unmarked } \\
\text { + logophoric } & \text { unmarked }
\end{array}
$$

The consequence is that use of the Pronoun Q-implicates that the speaker is not in a position to use the Anaphor because either he intends disjoint reference or he intends non-logophoricity.

So far, for this hypothetical diachronic progression we have adduced evidence only from Old English and the various mentioned creoles, but it seems to be largely, if not entirely, compatible with the diachronic hypotheses about the origins of reflexives advanced by Faltz (1985) on the basis of the few major recent typological reviews of reflexivity encoding. ${ }^{43}$ His findings are worth reviewing in detail. Faltz suggests (1985: $48 \mathrm{ff}$.) that the main typological distinction is between languages that have true, underived, pronominal reflexives (like Russian sebja and German $s_{i c h}{ }^{44}$ ) and those with compound reflexives. Compound reflexives are of different types:

(i) nominal head reflexives, usually modified by a possessive pronoun, as in Turkish kendi-me 'self-mine', 45

(ii) adjunct reflexives, based on a pronoun modified with a reflexive adjunct as in Old English hine-sylfne '3MSG-ACC + REFL' or Irish $\dot{e}$ féin 'him + REFL';

[43] There are a great number of more specialized works, for example on reflexive verbs. See Geniušienè, 1987 for references.

[44] From Proto-European * $s(w)$-, proto-Germanic *sik, a form lost in the development of English (Faltz, 1985: 210).

[45] This leaves reflexives like Japanese zibun, a nominal head without modifier, somewhat stranded; Faltz (1985: 49) suggests that they must either be assimilated to the true pronominal reflexives or analyzed as head + zero modifier. 
(iii) fused adjunct reflexives, like modern English where himself can no longer be analyzed simply as head + modifier.

In addition to all these types, we have verbal reflexivizers, often derived from cliticized pronominal or nominal reflexives (like French $s e+$ verb from Latin se) but ending up as true verbal affixes (like Russian middle -sja from pronominal sebja). Diagrammatically:

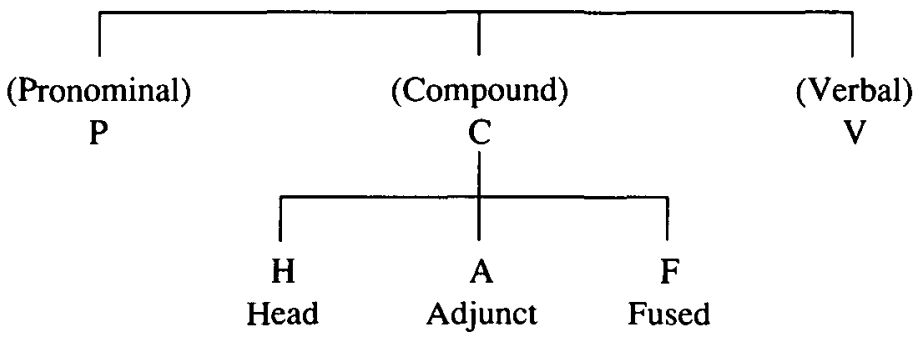

Certain properties are said to be restricted to each of these types. For example, $\mathbf{P}$ reflexives require subject antecedents, strictly require all coreferential clause-mates to be encoded with the $P$ form, but may have longdistance uses, while $\mathrm{C}$ reflexives tend to allow non-subject antecedents, allow some oblique non-reflexive co-referential clausemates, but do not permit 'long-range' uses. (It is clear in fact on the basis of more recent information that these could be at most systematic trends.)

Faltz (1985: ch. 6) then suggests that the following kinds of diachronic progressions may be hypothesized:

(i) All verbal reflexives come from NP reflexives via cliticization, thus: $\mathrm{P}>\mathrm{V}$ or $\mathrm{C}>\mathrm{V}$ together with an associated tendency for later semantic bleaching of the reflexive verb form to a 'middle' (or generalized intransitivizing) verb-form; reverse progressions do not occur, ${ }^{46}$ and it is hypothesized that there are no progressions $\mathrm{P}>\mathrm{C}$ or $\mathrm{C}>\mathrm{P}$ (Faltz 1985: 233 ff.).

(ii) Perhaps all $\mathrm{C}$ reflexives come from emphatic adjuncts on pronouns, as for instance Old English self, French même (from late Latin *met-ipsimum ${ }^{47}$ ),

[46] Faltz rejects (fn 6, p. 278) the idea that intransitivizing verbal affixes might specialize to become reflexives. Actually, though, this seems to be happening in the case of Guugu Yimidhirr anti-passive or middle (see Haviland, 1979; Levinson, 1987b), with reflexive specialization of the intransitivized verb being currently marked by an additional emphatic on the single NP. Of course, the Guugu Yimidhirr anti-passive might already have passed through a reflexive stage, with subsequent semantic bleaching, but some evidence against this is that some verbs (see Haviland, 1979: $126 \mathrm{f}$.) that obligatorily take anti-passive inflection (by some frozen, and thus presumably old, process) simply have an intransitive meaning (e.g. 'explode', 'shine', etc.).

[47] Nigel Vincent tells me that the Proto-Romance formation *met-ipsimum is a case of threefold emphasis: met was an emphatic (as in egomet 'I myself'), ipse was the standard Latin emphatic pronoun with case inflection, and -imum was the superlative suffix as found in maximum, etc. He adds that Italian stesso derives from iste-ipse, a double pronoun combination. 
Dutch zelf, Papago hijil, etc. (1985: 243 ff.); some of those based on forms glossing like 'his head/body' also clearly derive from emphatics (Biblical Hebrew), while others may possibly have been directly coined to encode reflexivization.

(iii) More speculatively, $\mathrm{P}$ pronouns derive from 'subordinate reflexives' (long-range-only reflexives). These are non-reflexive pronouns used coreferentially with non-clause-mate antecedents, like the logophoric African pronouns discussed above. ${ }^{48}$ These 'subordinate reflexives' in turn derive either from stressed pronouns or from a first-person pronoun used in direct reported speech. ${ }^{49}$

Thus, if in broad outline Faltz is right, nearly all reflexives ultimately arise from emphatic or stressed pronouns. ${ }^{50}$ As to why this might be the case, he advances what is in effect a brief and informal version of our B-first account: 'an emphatic is added to an NP as a warning to the hearer that the intended referent of that NP is unusual or unexpected' (1985: 240); 'in the absence of a reflexive strategy, it is natural for an emphatic to be used to signal that the more highly marked, less expected situation is present, namely that the NP (argument) in question has the same referent as another one in the same predication ' (ibid. 242). In addition to Old English, Faltz cites Dutch, French and Spanish secondary reflexives (même and mismo), Papago, Hebrew, and the like as providing clear evidence for reflexives derived from emphatics. ${ }^{51}$ The German secondary reflexive selbst is also interesting here; cognate with English self, it remains an intensifier used to mark reflexivity with nonsubject antecedents (the primary reflexive sich requiring a subject antecedent) as in:

(36) Hans sprach mit Fritz über ihn (selbst)

Hans spoke with Fritz about him (himself)

[48] Faltz does not appear to have been aware of Hagège's work, and makes no reference to the subjective point-of-view phenomena associated with long-distance reflexives, although he discusses some of the classic logophoric languages like Ewe (1985: 252).

[49] Of course the derivation of a long-distance reflexive from a first person pronoun in a language that has no system of indirect reported speech (in other words from a form glossable as 'John said I will come' to a form 'John said self would come') would make immediate sense of the logophoric associations of such pronouns. Faltz (1985: $263 \mathrm{ff}$.) notes a number of problems for such a development, although it seems eminently plausible for some of the African languages like Ewe. However, it is quite clear that this cannot be the source of all such long-distance reflexives with associated logophoricity, since these are (as Faltz notes, pp. 257 ff.) often (as in Igbo) clearly third-person in origin.

[50] The exceptions will be those derived from first person long-range-only 'reflexives', and any $\mathrm{C}$ forms of the 'body-his' kind that may have been directly coined.

[5I] The evidence is of different kinds; the weakest is mere overlap in function between emphatics and reflexive morphemes; stronger evidence, as in the case of Papago, is where this is reinforced by comparison with related languages where the morpheme only has a reflexive function; best of all, of course, as in the rest of the cited languages, is where there are records showing increased grammaticalization over time of the emphatic into a reflexive. 
In (36) without the addition of selbst reference of ihn is likely to be taken to be a third party, but with selbst the referent is taken to be Fritz (Faltz, 1985: 240). Note that selbst is also synchronically an intensifier

Der Präsident selbst wird kommen

'The President himself will come'

and a focus particle:

(38) Selbst der Präsident wird kommen

'Even the President will come'

the different scopes perhaps being responsible for the meaning differences in these usages (Edmondson \& Plank, I978; König, I99I, Ch. 8). Diachronically, the NP intensification use seems to be prior to all the others (König, op. cit.).

Although Faltz's account antedates the great upsurge of work on binding, it seems still to be the most comprehensive cross-linguistic survey of reflexivization available (although see also Geniušienè, 1987; Sells, Zaenen \& Zec, 1987) and it suggests that the account we are advancing may have some real cross-linguistic generality. Nevertheless, the evidence is still relatively thin, and still relatively biased by data from Indo-European languages. Clearly, we need much more work on the history of reflexives in those languages like Tamil, Chinese, Japanese, and others that provide long continuous records. In the history of all three of these languages, we can find evidence for at least a precondition for the reflexives-from-emphatics hypothesis, namely evidence for overlap in function of the same morpheme(s) for both emphasis and reflexivity. Thus, Classical Chinese $z i$ clearly had both reflexive and emphatic uses like modern Chinese ziji. ${ }^{52}$ Ancient Japanese had a range of reflexives that also functioned as subject intensifiers or emphatics ${ }^{53}$ modern zibun or jibun (the $j i$-morpheme is written with the same Chinese character as Classical $z i$ and is obviously borrowed) clearly maintains the emphatic adjunct function. ${ }^{54}$ Modern Tamil has the same tell-tale overlap

[52] Harbsmeier (1981: Ch. 3) contains some interesting material on Classical Chinese reflexives; he claims that pronominal $j i$ was a contrastive reflexive pronominal (related to, but distinct from the nominal $j i$ referring to the Taoist 'Self'; p. 178) with clausemate antecedents, but also a non-contrastive long-distance reflexive requiring co-reference with the subject of the highest clause (I87); while $z i$ clearly had emphatic functions of many sorts, just like the adverbial uses of modern Mandarin ziji (Li \& Thompson, I98I : 138).

[53] See Syromiatnikov (I98I: 8I f.) who notes both reflexive and emphatic adjunct uses for onöre and midukara in Ancient Japanese (cf. Modern Japanese mizukara, an alternate to zibun, Hinds, 1986: I16). These seem to be bleached head nominals (kara means 'body'), a common reflexive source classified by Faltz (1985) as a kind of $\mathrm{C}$ pronoun.

[54] Although rarely mentioned in the recent theoretical literature on jibun/zibun (Kuno, 1973; Hinds, 1986 and Sells, 1987 are all silent on this point), the emphatic functions figure prominently in traditional pedagogical grammars. Thus, Vaccari \& Vaccari (1948: $358 \mathrm{ff}$.) list uses similar to English He himself came, I bought it myself; they even note the double emphatic use of jibun jishin to translate 'you did it yourself' (lit. ji-bun 'self-part', ji-shin 'self-body'). 
in function of the morpheme taan as an indeclinable NP intensifier and a declinable (long-distance) reflexive; in Classical Tamil, the intensifier was a declinable post-position (Andronov, I969; 108). The tendency to pronominalize is continuing in the more recent use of taan as a non-reflexive honorific second (or sometimes third) person pronoun. Even in the presentday language, the emphatic and the reflexive are more than mere homophones: 'with regard to the emphatic marker taan, one might wish to say that there is some semantic overlap with the reflexive pronoun taan', another emphatic affix -ee sometimes also being used to indicate reflexivity (Asher, I 985: 86). As Caldwell (I96I[I856]: 40I) noted over a century ago, Dravidian taan 'must, I think, have originated from some emphatic demonstrative base', a conclusion supported by later comparative Dravidian studies. For example, Gondi tanaa is 'only used in the third person and in the nominative' (Burrow \& Emeneau, I96I: 207), that is, I suspect, purely as an emphatic adjunct.

Still, whatever the current empirical basis, the hypothesis seems plausible enough, and it is certainly open to empirical refutation. It clearly makes interesting predictions about the evolution of anaphoric patterns generally. It suggests for example that languages with long-distance reflexives may be mid-way between A-first and B-first patterns, and if so, we might expect a greater flexibility in interpretation in such languages than in English. Chinese is an interesting case in point, and it is worth seeing how the facts might be incorporated into an account of this sort.

In a thorough re-examination of Chinese anaphora, Y. Huang (I989, I990) claims (no doubt controversially, but nevertheless convincingly) that no grammatical account of the GB-type will be able to handle the observed flexibility of interpretation. Thus he argues for a pragmatic explanation of the patterns, but he claims that my A-first account (as in Levinson, 1987b) will not work, largely because on that account there should be a strong tendency (via Q-implicature) for the complementary interpretation of Anaphors and Pronominals, whereas in Chinese that is not the case. Instead, he opts for something close to my B-first account, making use only of $\mathbf{M}$ - and I-implicatures (with that order of priority), together with a presumption of intra-clause argument distinctness (attributable to I). This appears to work well to predict the favoured anaphoric interpretations; in effect there is a global tendency to locally co-referential readings of both the reflexive ziji and the non-reflexive pronoun $t a$, a tendency defeated in the case of $t a$ with a potential clausemate antecedent by the presumption of core-argument distinctness. But it is clear that Chinese does have, in the case of ziji, a pronominal that is obligatorily referentially dependent (which we take to be a semantic fact) without a clear syntactic specification of a binding domain. The synchronic state of the language may then reflect a period of transition towards an A-first system with grammaticalized Anaphors, with ziji being in the process of acquiring the Q-contrasts so typical of A-first languages. 
Unfortunately, there seems to be no history of pronominals and reflexives in Chinese easily accessible to the non-specialist. Perhaps some speculation may be forgiven in the hope that specialists may be goaded into supplying us with the facts. As already mentioned, ziji already in Classical Chinese had both emphatic and reflexive uses, and it continues to be used as an intensifier, for example in collocation with a subject ( $\mathrm{Li} \&$ Thompson, I98I : I38 f.). Thus, on the hypothesis that $z i j i$ was in origin an emphatic, we can postulate an earlier B-first state of the language with the following properties:

(a) INTRA-CLAUSAL ANAPHORIC PATTERNS: use of the pronominal $t a$ would tend to I-implicate local co-reference, except with clausemate antecedents where the presumption of clausemate argument distinctness would block coreference. This presumption is over-ruled by the use of a marked, emphatic ta ziji or $z i j i$ which would $\mathrm{M}$-implicate the complementary interpretation, here co-reference.

(b) CROSS-CLAUSE ANAPHORIC PATTERNS: here, where there is no presumption of disjoint reference, $t a$ will tend to pick up a local antecedent. The use of ( $t a)$ ziji will M-implicate a contrastive interpretation, but not necessarily a contrast in reference (no longer especially salient, given the irrelevance of the presumption of clausemate argument distinctness). The contrast may be on the dimensions of unexpectedness, sole agency or nondeictic ('logophoric') point of view. ${ }^{55}$

Later, through the usages in (a), ziji must have acquired specific semantic content, namely necessary referential dependence.

In the modern language, given that $t a$ encompasses both deictic and anaphoric uses, there is now an ordering of semantic informativeness over the two expressions, and thus the makings of a Horn-scale $\langle z i j i, t a\rangle$, with the use of the weaker $t a$ suggesting that the use of ziji would be inappropriate. But ziji, even in the present language, is not an Anaphor in the classic GB sense, since it carries no specification of the domain in which it must be bound (Y. Huang, 1989: $90 \mathrm{ff}$.). The Q-opposition between ziji and $t a$ is thus rather weak - ziji is no more informative about where to find an antecedent,

[55] It is notable that in modern Chinese there is often a contrast in preferred referential interpretation of embedded pronominals that favours a local antecedent for $t a$ and a more distant one for $z i j i$. For example, Huang (1989: $9 \mathrm{I}$ ) notes of the following kind of example that the favoured interpretation co-identifies Wang (rather than $L i$ ) and $z i j i$ :

(i) Lao Wang yiwei Lao Li bu zhidao ziji qu guo Meiguo Lao Wang think Lao Li not know self go EXP America 'Wang thinks that Li doesn't know that self has been to America.'

This tendency for $z i j i$ linkage to skip over a good candidate antecedent which would have been the favoured link with ta may therefore by partially explained by this pragmatic theory (specifically, the M-contrast between $t a$ and $z i j i)$. Huang ( $1989: 106 \mathrm{fn} .6$ ) points out that a similar pattern has been noted for Japanese. However, our account cannot be the full explanation because even where there is no contrast with $t a, z i j i$ still prefers a more distant antecedent. For instance, in a sentence with only one embedded clause glossable as 'Wang thinks $\mathrm{Li}$ has fallen in love with PRONOMINAL', the nearest antecedent, $\mathrm{Li}$, is a clausemate disfavouring identification with $t a$, but $z i j i$ would still naturally refer to Wang. 
and, after all, most pronominal uses are anaphoric, and thus referentially dependent in any case. What will strengthen the opposition is the encoding of contrast or unexpectedness, emphasis and 'logophoricity' associated with ziji. The use of $t a$ will therefore suggest (Q-implicate) that either the speaker wishes to avoid referential dependence or that he wishes to avoid the 'logophoric' or contrastive associations of ziji. Where reference is the salient issue (especially, where there is a potential intra-clause antecedent such that the presumption of intra-clausal argument distinctiveness is pertinent), the use of $t a$ will strongly suggest disjoint reference, ${ }^{56}$ but elsewhere it is just as likely to suggest non-contrastiveness or non-logophoricity. So we obtain the following patterns of preferred interpretation (from Huang, I989: ch. 3):

(40) (a) Lao Wang piping le ziji

Lao Wang criticize PFV self

'Wang ${ }_{1}$ has criticized himself,

(b) Lao Wang piping le ta

Lao Wang criticize PFV $3 S G$

' Wang $_{1}$ has criticized him ${ }_{2}$ '

(4I) (a) Lao Wang shuo ziji shi ge gongchengshi

Lao Wang say self be CL engineer

' $\mathrm{Wang}_{1}$ says that he ${ }_{1}$ himself is an engineer'

(b) Lao Wang shuo ta shi ge gongchengshi

Lao Wang say 3 sG be CL engineer

' Wang $_{1}$ says that he $_{1}$ is an engineer'

Thus disjoint vs. conjoint reference is the most salient opposition between $t a$ and $z i j i$ within the clause, while the subjective, 'logophoric' contrast is the most salient opposition outside it. Y. Huang's (1989) own account of all this is simpler: in (4ob) the presumption of clausemate argument distinctness over-rides the I-preference for local co-reference, while the latter in turn is over-ridden by the semantics of referential dependency in (40a). In (4I) the preference for co-reference goes through unchecked.

Yet Huang's account leaves questions unanswered, for example why the $t a / z i j i$ opposition fails to form a Q-implicating Horn-scale. It also, perhaps, hides the cross-linguistic generality of these patterns: if we bring the subjective meaning ('logophoric') contrasts back into the picture we can see why we can have a pragmatic contrast without a change of reference. These contrasts, subtle though they are, are surely a prominent part of these systems, partially eclipsed by the focus on referential potential in grammatical theory, but correctly emphasized in recent work by O'Connor (1987), Kuno (1987), Sells (1987), Stirling (1988) and others. The contrast between $t a$ and

[56] That this is only a suggestion was clear, Huang (1989: 54) points out, to traditional grammarians of Chinese; he quotes Wang Li: "As for ta ma ta ("He rebukes him"), it is ambiguous: it can mean either "he rebukes himself" or "he rebukes another person". 
$z i j i$ is therefore often interpreted non-referentially, as acknowledged in Huang (1990), where $z i j i$ is claimed to carry an 'unexpectedness message' indicating either logophoric viewpoint or contrastiveness, when used in positions where a pronoun or zero anaphor could have the same reference.

We are also enabled to see rather striking parallels, for example between (in just this limited respect) modern Chinese and Old (and Middle) English. Consider, for example, the possibility of the following anaphoric links. ${ }^{57}$

(42) (a) Wang Xiaojie feichang xinshang ta ziji Wang Miss very admire 3SG self Miss Wang ${ }_{1}$ admires her-herself ${ }_{2}$ very much

(b) Moyses, se ðe wæs Gode sua weorð ðæt he oft Moses he who was to God so dear that he often wið hine selfne spræc with himself spoke 'Moses, who was so dear to $\mathrm{God}_{2}$ that he ${ }_{1}$ often spoke with [God] himself ${ }_{2}$,

The seeming paradox of these usages (with 'reflexives' and plain pronominals having reversed functions) evaporates if we keep in mind the emphatic origins of the reflexive: then we can see that a pronominal plus an emphatic might naturally send one (via $\mathrm{M}$-implicature) to the complement of the (coreferential) interpretation that would have been most salient from the use of a simple pronoun. Likewise, the parallels to Chinese in the "long-range reflexive' uses of the -self forms in Old English can be brought out:

(43) (a) Xiaoming yiwei mama yao zeguai ziji le Xiaoming think mum will blame self CRS Xiaoming $_{1}$ thinks that Mum $_{2}$ will blame self

(b) He [Gregorius] Almihtigne God bæd pæt he Almighty God prayed that ' $\mathrm{He}_{1}$ prayed to Almighty $\mathrm{God}_{2}$ that he hi mid his gife gescylde: he to them with his grace should bestow $\mathrm{He}_{2}$ should bestow $\mathrm{His}_{2}$ grace upon them:

7 pæt he him seolfum forgeafe pæt $\&$ that he to him self would grant that and that $\mathrm{He}_{2}$ to himself $f_{1}$ would grant that

[57] The Chinese example is from Huang, 1989: 96, the source of the Old English example is cited in footnote 38 (see Mitchell, 1985: 115). I am grateful to April McMahon for help in interpreting the Old English examples. 


\section{REDUCTION OF BINDING CONDITIONS}

he moste done wæstm heora gewinnes he might the fruits of their labours $\mathrm{he}_{1}$ might see the fruits of their labours in heofona rices wuldre geseon. in heaven's kingdom's glory see in the glory of the Kingdom of Heaven.'

In the Chinese, the search for an antecedent for ziji can happily leap over a clausemate subject, finding an antecedent in a matrix clause (Huang, 1989: $50 ;$; 9 I ff.). Similarly, Mitchell (1985: 194) argues that him seolfum in this extract from Bede 'refers to Gregorius, the subject of the main clause, and not to God, the subject of the clause in which it stands'. Thus the passage glossed ' $\mathrm{He}_{1}$ prayed to Almighty $\mathrm{God}_{2} \ldots$ that $\mathrm{He}_{2}$ would grant to himself $\ldots$...' has just the same pattern of anaphora as the Chinese sentence. Mitchell points out that often the -self form in Old English 'is in effect reflexive, though not grammatically so' in just this way.

These are surely striking parallels across time and linguistic phylogeny. In both Old (and perhaps especially later Middle) English and Chinese, we seem to be dealing with a flexible system of anaphoric interpretation, with only very partial coding of 'Anaphoricity' (that is to say referential dependency within a restricted domain), where the referentially dependent pronominal clearly has primordial emphatic or intensification functions which continue to effect its use. In the case of English, we know the further direction of development, towards true Anaphors with restrictive binding domains; it may not be entirely fanciful to imagine that Chinese is heading in the same direction, towards an A-first system. But regardless of that, the categories Afirst, B-first and 'in-between' may provide a useful, if crude, first step towards a cross-linguistic typology of anaphoric systems, providing that they are taken together with the pragmatic principles that generate the patterns and severely restrict the possibilities of preferred interpretation.

\section{Conclusions}

This paper has re-examined my earlier A-first account (Levinson, 1987a, b), which attempts to reduce Binding Conditions $B$ and $C$ to matters of generalized conversational implicature using the apparatus independently motivated by much work in pragmatics. I have tried to deal with some of the difficulties that have arisen, and in so doing have shown how the account may be extended to cover some of the facts about long-distance reflexives and the overlapping distribution of pronouns and reflexives with the same reference. However, the A-first account is clearly inapplicable to languages that lack reflexives altogether, so for such B-first languages I have shown how the same Gricean pragmatic principles can be used to predict a rather different strategy for indicating co-reference and disjoint reference. While the 
A-first account explains how anaphoric patterns are projected from Gricean principles applied to grammaticalized Anaphors, the B-first account shows how grammaticalized Anaphors might arise in the first place. Thus it seems natural to suppose that all A-first languages have derived from B-first ones. If we take this diachronic perspective, linking our A-first and B-first accounts, we are then provided with a plausible account - it would seem for the first time - of the persistent association of logophoricity and long-range reflexives.

Such an account of anaphoric patterns in terms of a theory of preferred interpretation of the sort offered by the neo-Gricean theory of generalized conversational implicature is interesting for a number of reasons. First, it seems to fall out of independently motivated Gricean principles, together with reasonably intricate projection rules for inconsistent potential implicatures (especially the hierarchy of preference $Q>M>I$ ). The system is rich enough to make strong restrictive predictions, and that they happen to be in the right direction is encouraging. Secondly, an account of this sort integrates the facts about 'logophoricity' which on a grammatical account (at least in GB terms ${ }^{58}$ ) are irrelevant and unexplained. Thirdly, it makes interesting typological and diachronic predictions, which seem to fit the fragmentary evidence in so far as I control it.

The integration of a pragmatic account of anaphora with a diachronic perspective is natural, but nonetheless in need of further development. Clearly, on this account, anaphoric patterns are accretions of habitual usages motivated by rational functional principles, but which in becoming conventionalized make available yet further pragmatic exploitations. The patterns are learnable on the basis of evidence for the use of language taken together with the rational principles underlying language use. The time scale for 'evolution' of one system into another (say a B-first system into an A-first system), or of the emergence of true Anaphors, may be measured in hundreds of yèars. All this, of course, seems clearly at variance with a GB perspective, where anaphoric patterns are instantiations of mental templates, are considered to be in principle unlearnable, and where parameter switching can only take place within the space of a single generation.

The general issues raised call for far more detailed discussion than space allows here. But it is essential to emphasize that there is no general challenge here to some concept of a rich, restrictive innate linguistic ability or Universal Grammar. Nevertheless the possibility of a pragmatic account of the core patterns of anaphora must raise doubts about whether these play as central a part in our innate linguistic endowment as so much current linguistic theorizing presumes. Equally, there is no suggestion here that the current patterns of anaphora in, say, English, are entirely pragmatic - rather

[58] See though such works as Hellan (1988) where an attempt is made to integrate the logophoric facts with a binding account. 
that the central facts can be seen to have functional motivation, that diachronic explanations might refer more to pragmatic principles than to principles of UG, and that defeasibilities of interpretation, at the margins as it were, are the stigmata of the functional origin of currently grammaticalized patterns. Thus the presumed inability of a pragmatic account to predict, for example, the details of reflexives in so-called Raising or Exceptional Case Marking contexts (as in John believes himself to be ill) does not undermine the thrust of the argument: once a language has grammaticalized an A-first system, such a system will have to treat such weakened clause boundaries one way or the other, as permeable or impermeable barriers to binding.

Two specific issues however should be briefly taken up - the implications for language learning and language change. The facts adduced above about B-first languages and their slow mutation into A-first languages do not sit well with the kind of language learning model associated with GB. Take for example Wexler and Manzini's (1987) account of the parameterization of the Binding Conditions. For a language to be learnable despite the absence of 'negative evidence' (feedback that certain sentences are ungrammatical), there must be some mechanism to stop overgeneralization, such as a preference for the 'smallest' language consistent with the data. Wexler and Manzini suggest this is achieved by ensuring that for any two values $i$ and $j$ of a parameter $\mathrm{P}$, the language $\mathrm{L}(i)$ generated by the $i$ value will be a proper subset of the language $\mathrm{L}(j)$ generated by the $j$ value (the 'subset principle'). The Binding Conditions can be parameterized by varying (to put it informally) the 'size' of the binding domain or minimal governing category (MGC). For example, a very general specification as for English binding (minimal S or NP with a subject) will result in a 'smaller' MGC than a very specific requirement (like indicative clause) that will result in a 'larger' MGC as for Icelandic long reflexives. Then one can generalize: the 'smaller' the MGC or binding domain for Anaphors, the 'smaller' the language. Consequently, the language learner should assume the smallest MGC compatible with the data, and the unmarked value (or initial setting) of the parameter will specify the minimal MGC. However, applying the same reasoning to pronominals gives the reverse prediction: the 'larger' the MGC or binding domain for Pronominals, the 'smaller' the language. Therefore Wexler and Manzini relativize the binding domain parameter to specific lexical items, specific Anaphors or Pronominals as the case may be (they adduce Icelandic data that seem to require this anyway), not without an unhappy loss of any language-wide generalizations.

Consider now the facts about B-first languages in the light of such a learning theory. In a B-first language, as we have seen, pronouns can be referentially dependent, or not, in any domain whatsoever. If we treat them as Anaphors, then the MGC in which they must be bound is maximal (root $S$ or discourse) and the resulting language is maximal and highly marked. If we treat them as Pronominals, the MGC in which they must be free is 
minimal (NP or smaller) and the resulting language is maximal and highly marked. If we treat them as ambiguous, such languages would present no evidence for determining the extent of the MGC and no criteria for a principled distinction between Anaphor and Pronominal. ${ }^{59}$ If we treat them as simultaneously вотH Anaphors and Pronominals then they should have the highly restricted distribution of PRO. But think of the dilemma for the language learner: how could he or she ever determine the categorization into Pronominal or Anaphor? And if ambiguity was suspected, how could the evidence resolve which homophonous instance was a Pronominal or an Anaphor? Now consider that the evidence would seem to show that early stages of pidgins and creoles are B-first languages, as discussed above, with the frequent use of non-reflexive pronouns as Anaphors. Recollect too that children seem to use non-reflexive pronouns readily as Anaphors in the same way. Indeed, in Solan's (1987) experiments, four to six-year-olds interpreted English non-reflexive pronouns as 'free' Pronominals on average only $34 \%$ of the time. Thus in both pidgin and creole languages and in child language we find properties typical of B-first languages. The Wexler and Manzini results would make these properties the most marked settings of the Binding parameters - as far from the presumed initial UG settings as possible! This is clearly not the right result. ${ }^{60}$

Consider by contrast an emergent A-first language, with emphatic NPs beginning to act routinely as Anaphors with clausemate antecedents. The language learner looking for an Anaphor might correctly detect these NPs as candidates, might attempt to analyze them as locally bound within a minimal MGC, but would find other co-referential emphatic NPs homophonous in form in non-local positions, and would be led (one would expect) to the maximal marked setting of the MGC. On a theory, like Wexler and Manzini's, which necessarily decouples the parameter settings of MGCs for Anaphors and Pronominals, it is hard to see how to get the language learner to focus on the crucial opposition between alternative realizations of clausemate NPs. ${ }^{61}$

Compare all these difficulties now with the comparable ones for a pragmatic account. The evidence for the Q- and I-principles abound in many aspects of language data (see for instance Atlas \& Levinson, I98I; Levinson,

[59] For an attempt to argue for ambiguity, see Chung (1989). More generally, theorists like Koster (1986: $34 \mathrm{I}$ ff.) seem willing to propose that pronouns are ambiguously Anaphors and Pronominals while reflexives may equally be Anaphors or Pronominals (as in John himself came), without considering the implications for a theory of acquisition.

[60] There are other inconsistent findings: for instance, Sigurjonsdottir \& Hyams (I988) have found that children learn the use of the Icelandic long reflexive sig relatively early, without passing through a stage of experimenting with more minimal MGCs. See the discussion in Lightfoot, 1989: 370-371.

[61] Although Lightfoot's (1989) idea that, despite appearances to the contrary, all parameters can be (and therefore presumably should be) set on the basis of root clause phenomena might offer some succour. 


\section{REDUCTION OF BINDING CONDITIONS}

$1987 \mathrm{a}, \mathrm{b}$; Horn, I $985, \mathrm{I} 989$, etc.). True, it is not clear exactly how the learner comes to formulate such principles, some like Sperber and Wilson (1986) presuming that something similar to them derives directly from innate predispositions to process information in certain ways, others like Grice and those who follow him more closely (including the present author) imagining that they arise from some complex interaction between native rationality and the demands of the communication setting (see Levinson, 1989). Be that as it may, such inferential principles (or something like them) indubitably exist and are clearly utilized (to growing extents) by the language learner, as are many other not specifically linguistic inferential procedures. Patterns of anaphora will then be inspected to see whether they can be treated as instantiations of Q- or M-oppositions to the I-based tendency to stereotypical readings. If anaphoric patterns are learnt this way, then there are clear predictions for acquisition based on the fact that the patterns arise from contrastive opposition. For example, in an A-first language, where Principle B patterns are parasitic on Principle A patterns, Principle A patterns would have to be learnt first. And so in fact they seem to be. ${ }^{62}$ This is in contrast to the Wexler and Manzini predictions, which not only decouple A and B patterns, but relativize them to particular lexical instantiations of Anaphors and Pronominals; there is no reason then why B patterns might not come first.

Let us turn finally to the implications of all this for language change. The parameter setting model has implications of course for how one would expect such change to occur: Lightfoot (1989: 325) suggests it should happen because a structural reanalysis by the language learner of some syntactic patterns (a parameter switch) may force certain data to be ignored as 'impossible data', not part of the 'trigger (parameter setting) experience'. Vincent ( 1989 a: 361 ) comments that one would then expect a certain special kind of obsolescence, notable for 'the relatively sudden disappearance from attested sources'. For example, once a himself form is analyzed as an Anaphor bound within a minimal MGC, one might expect rapid loss of homophonous forms bound further afield; or once him is analyzed as a Pronominal free in a maximal MGC, one would expect rapid squeezing out of the use of him as a reflexive. The loss should take place in transmission across one generation, and although one must allow for sociolinguistic diffusion across a population, individuals' usage should be consistent

[62] Apart from the delayed acquisition of Binding B patterns found by Solan and others mentioned above, Reinhart (1986: 140-142) notes that findings about childrens' use of backward anaphora favour treating Binding $B$ patterns as pragmatic. She argues that the data support her particular A-first analysis, with all types of bound anaphora collectively distinguished from pragmatic anaphora. Her argument, like ours, is based on the presumption that innate predispositions should show up earlier in acquisition than pragmatically determined patterns. 
(Lightfoot, 1989: 370) ${ }^{63}$ But again none of these predictions seem true of the history of anaphora in English, or indeed other languages, where the establishment of for example Principle B type patterns of usage began in Anglo-Saxon times but was still not complete in Shakespeare's. All this suggests that if language learning does indeed generally proceed by the setting of parameters, the view that Binding domains are candidate parameters does not have obvious empirical support from the facts of acquisition or the indirect effects that modes of acquisition might have on language change.

There are striking cross-linguistic parallels in anaphoric patterns. There are also some striking exceptions to what we have come to expect (like the B-first languages). Finding a satisfactory explanation of both the deep parallels and the anomalies is going to be difficult. It will clearly involve a universal theory of construal tendencies and the way this interacts with language specific details. One model for such an explanation is a parameterized Binding theory interacting with other parameters in an innate language learning device. Another model, the one being suggested here, is a universal pragmatic theory that covers the anaphoric tendencies, interacting with language specific details that are partly historical accretions of practices.

Author's address: Max Planck Research Group for Cognitive Anthropology,

Wundtlaan $I$,

NL $6525 X D$ Nijmegen,

The Netherlands

\section{REFERENCES}

Adams, M. (1987). From Old French to the theory of pro-drop. Natural Language and Linguistic Theory 5. I-32.

Anderson, S. R. (1986). The typology of anaphoric dependencies. In Hellan \& Koch Christensen. 65-102.

Andronov, M. (1969). A standard grammar of modern and classical Tamil. Madras: New Century Book House.

[63] Bite draws my attention to a parallel case: Platzack's (1987) consideration of the time scale for the parameter switch from null subjects to realized subjects in Swedish. Platzack argues that there are a number of syntactic reflexes of this parameter (among others subject-verb agreement, expletive pronouns vs. gaps, and that-trace filter violations), and that the historical record shows that 'these changes occurred together during a relatively short space of time-more or less within the seventeenth century' and that this supports 'the hypothesis that they are all reflexes of a single parameter in the grammar' (Platzack, 1987: $397 \mathrm{f}$.). The statistics he produces for frequency of null-subjects might support a slightly more gradual account, in terms perhaps of a two hundred year process; and there were also special sociolinguistic factors during this period of major state formation (as he points out). Nevertheless, there is a rather striking contrast in timescale between this Swedish case, with relatively rapid linked changes, and the history of English anaphora with the very slow acquisition of Anaphors and the apparent lack of linkage between acquisition of something like Principle A, on the one hand, and Principle B type patterns on the other. For a more sceptical view, see Kroch (1989), who maintains that most linguistic change is likely to be gradual, and that language learners may happily operate with two slightly inconsistent grammars, making rapid parametric change unlikely. See also the much more gradual loss of pro-drop in Old/Middle French analyzed in Adams (1987). 


\section{REDUCTION OF BINDING CONDITIONS}

Asher, R. (1985). Tamil. London: Croom Helm.

Atlas, J. D. \& Levinson, S. C. (1981). It-clefts, informativeness and logical form: radical pragmatics (revised standard version). In Cole, P. (ed) Radical pragmatics. New York: Academic Press. I-6I.

Atlas, J. D. (1989). Topic/comment, presupposition and logical form: the case of focal adverbs only and also. Paper presented to the Fokus Workshop, Stuttgart, 30 June 1989.

Austin, P. (1987). Cases and clauses in Jiwarli, Western Australia. MS, La Trobe University, Melbourne.

Battistella, E. (1985). On the distribution of PRO in Chinese. Natural Language and Linguistic Theory 6. 19-37.

Battistella, E. (1989). Chinese reflexivization: a movement to INFL approach. Linguistics 27. 987-1012.

Bickerton, D. (1981). Roots of language. Ann Arbor: Karoma.

Bouchard, D. (1983). On the content of empty categories. Dordrecht: Foris.

Burrow, T. \& Emeneau, M. (1961). A Dravidian etymological dictionary. Oxford: Clarendon Press.

Burzio, L. (1991). The morphological basis of anaphora. This volume.

Caldwell, Bishop R. (1961) [1856]. A comparative grammar of the Dravidian or South-Indian family of languages. Madras: Madras University Press. [Originally London: Harrison.]

Cantrall, W. R. (1973). Why I would relate own, emphatic reflexives, and intensive pronouns, my own self. Papers from the 9th Regional Meeting of the Chicago Linguistics Society. 57-67.

Cantrall, W. R. (1974). Viewpoint, reflexives, and the nature of noun phrases. The Hague: Mouton.

Carden, G. \& Stewart, W. (1986). Binding theory, bioprogram and creolization : evidence from Haitian creole. Paper presented at LSA annual meeting. To appear in Journal of Pidgin \&

Carden, G. \& Stewart, W. (1987). Mauritian creole reflexives - an alternative historical scenario. MS, University of British Columbia.

Carden, G. \& Stewart, W. (1988). Binding theory, bioprogram and creolization: evidence from Haitian Creole. Journal of Pidgin and Creole Languages 3. 1-67.

Carden, G. \& Stewart, W. (1989). Mauritian Creole reflexives: a reply to Corne. Journal of Pidgin and Creole Languages. 4. 65-10I.

Chomsky, N. (1981). Lectures on government and binding. Dordrecht: Foris.

Chomsky, N. (1986). Knowledge of language. New York: Praeger.

Chung, S. (I989). On the notion 'null anaphor' in Chamorro. In Jaeggli \& Safir. I43-I84.

Corne, C. (1988). Mauritian creole reflexives. Journal of Pidgin \& Creole Languages 3. 69-94.

Dirven, R. (1973). Emphatic and reflexive in English and Dutch. Leuvense Bijdragen 63. 285-299.

Dixon, R. M. W. (1980). The languages of Australia. Cambridge: Cambridge University Press.

Dixon, R. M. W. (I981). Wargamay. In Dixon \& Blake. Vol. 2. I-143.

Dixon, R. M. W. (1983). Nyawaygi. In Dixon \& Blake. Vol. 3. 431-525.

Dixon, R. M. W. (1988). A grammar of Bouma'a Fijian. Chicago: University of Chicago Press.

Dixon, R. M. W. \& Blake, B. (1979-83). Handbook of Australian languages. Vols 1-3. Canberra : ANU Press and Amsterdam: John Benjamins.

Eades, D. (1979). Gumbaynggir. In Dixon \& Blake. Vol. I. 245-36I.

Edmondson, J. A. \& Plank, F. (1978). Great expectations: an intensive self analysis. Linguistics \& Philosophy 2. 373-413.

Everaert, M. (1986). The syntax of reflexivization. Dordrecht: Foris.

Faltz, L. M. (1977). Reflexivization: a study in universal syntax. PhD thesis, U.C. Berkeley.

Faltz, L. M. (1985). Reflexivization: a study in universal syntax. (Revised version of Faltz, 1977.) New York: Garland.

Farmer, A. \& Harnish, M. (1987). Communicative reference with pronouns. In Papi \& Verschueren.

Fauconnier, G. (1975). Pragmatic scales and logical structure. LIn 6. 353-375.

Foley \& Van Valin (1983). Functional syntax and universal grammar. Cambridge: Cambridge University Press.

Gazdar, G. (1979). Pragmatics: implicature, presupposition and logical form. New York: Academic Press.

Geach, P. T. (1972). Logic matters. Oxford: Blackwell. 
Geniušienè, E. (1987). The typology of reflexives. Berlin: Mouton de Gruyter.

Grice, H. P. (1967). Logic and conversation. Unpublished manuscript of the William James Lectures, Harvard University; later published in Grice, 1989. Studies in the way of words. Cambridge, MA: Harvard University Press.

Hagège, C. (1974). Les pronoms logophoriques. Bulletin de la Société de Linguistique de Paris. 69. $287-310$.

Harbsmeier, C. (1981). Aspects of Classical Chinese syntax. London: Curzon Press.

Haviland, J. B. (1979). Guugu Yimidhirr. In Dixon \& Blake. Vol. 1. 27-180.

Hawkins, J. (I 986). A comparative typology of English and German. London: Croom Helm.

Hellan, L. \& Koch Christensen, K. (eds) (I986). Topics in Scandinavian syntax. Dordrecht: Reidel.

Hellan, L. (1986). On anaphora and predication in Norwegian. In Hellan \& Koch Christensen. 103-124.

Hellan, L. (1988). Anaphora in Norwegian and the theory of grammar. Dordrecht: Foris.

Higginbotham, J. (1980). Pronouns and bound variables. LIn Ir. 679-708.

Higginbotham, J. (1983). Logical form, binding and nominals. LIn I4. 395-420.

Hinds, J. (1986). Japanese. London: Croom Helm.

Hintikka, J. (1970). On attributions of 'self-knowledge'. The Journal of Philosophy 67. 7387.

Horn, L. R. (1985). Towards a new taxonomy for pragmatic inference: Q- and R-based implicature. In Schiffrin, D. (ed.) Meaning, form and use in context. Washington: Georgetown University Press. II-42.

Horn, L. R. (1989). A natural history of negation. Chicago: University of Chicago Press.

Huang, C-T. J. (1982). Logical relations in Chinese and the theory of grammar. Unpublished PhD dissertation, MIT.

Huang, C-T. J. (1983). A note on the Binding Theory. LIn 4. 554-56I.

Huang, C-T. J. (I 984). On the distribution \& reference of empty pronouns. LIn $15.531-574$.

Huang, Y. (1989). Anaphora in Chinese: towards a pragmatic analysis. Unpublished Ph.D, Linguistics Dept, University of Cambridge.

Huang, Y. (1990). Anaphora in Chinese: towards a neo-Gricean pragmatic analysis. MS, University of Cambridge Linguistics Department.

Iatridou, S. (1986). An anaphor not bound in its governing category. LIn 17. $766-770$.

Jaeggli, O. \& Safir, K. (eds) (1989). The null subject parameter. Dordrecht : Kluwer.

Jakubowicz, C. (1984). On markedness and binding principles. Proceedings of the North Eastern Linguistics Society 14.

Jespersen, O. (1927). A Modern English grammar on historical principles Part III (Syntax, second volume). Heidelberg: Carl Winters Universitätsbuchhandlung.

Kay, P. (1987). Even. Berkeley Cognitive Science Report No. 50. Institute of Cognitive Studies, U. C. Berkeley.

Keenan, E. L. (1988). On semantics and the binding theory. In Hawkins, J. (ed.) Explaining language universals. Oxford: Basil Blackwell. 105-144.

König, E. (199I). The meaning of focus particles: a comparative perspective. London: Croom Helm.

Koster, J. (1986). Domains and dynasties: the radical autonomy of syntax. Dordrecht: Foris.

Kroch, A. (1989). Language learning and language change. Behavioral and Brain Sciences 12. 348-349.

Kuno, S. (1973). The structure of the Japanese language. Cambridge, MA: MIT Press.

Kuno, S. (1987). Functional syntax. Chicago: University of Chicago Press.

Lakoff, G. (1968). Pronouns and reference. Mimeo. Indiana University Linguistics Club.

Langacker, R. W. \& Munro, P. (1975). Passives and their meaning. Lg 51. 789-830.

Levinson, S. (1983). Pragmatics. Cambridge: Cambridge University Press.

Levinson, S. (1987a). Minimization and conversational inference. In Papi \& Verschueren. $6 \mathrm{I}-129$.

Levinson, S. (I987b). Pragmatics and the grammar of anaphora. $J L$ 23. 379-434.

Levinson, S. C. (1988). Putting linguistics on a proper footing: explorations in Goffman's concepts of participation. In Drew, P. \& Wootton, A. (eds) Erving Goofman : exploring the interaction order. Cambridge: Polity Press. 161-228.

Levinson, S. C. (1989). Relevance. $J L$ 25. 455-472.

Levinson, S. C. (in prep) Generalized conversational implicature. Cambridge: Cambridge University Press. 


\section{REDUCTION OF BINDING CONDITIONS}

Li, C. \& Thompson, S. (1981). Mandarin Chinese: a functional reference grammar. Berkeley: University of California Press.

Lightfoot, D. (1989). The child's trigger experience: degree-O learnability. (With open peer commentary.) Behavioral and Brain Sciences 12. 321-375.

Lust, B. (ed.) (1986). Studies in the acquisition of anaphora. Dordrecht: Reidel.

Maling, J. (1984). Non-clause-bounded reflexives in Modern Icelandic. Linguistics and Philosophy 7. 2 I 1-24I.

Mitchell, B. (1985). Old English syntax. Vol. I. Concord, the parts of speech, and the sentence. Oxford: Clarendon Press.

Moravcsik, E. A. (1972). Some cross-linguistic generalizations about intensifier constructions. Papers from the 8th Regional Meeting of the Chicago Linguistic Society. 271-277.

Moyne, J. A. (I97I). Reflexive and emphatic. $L g$ 47. I4I-I63.

O'Connor, K. (I987). Disjoint reference \& pragmatic inference : anaphora \& switch reference in N. Pomo. Paper presented to Wenner-Gren Conference on 'The role of theory in language description', Jamaica, Nov. 1987.

Papi, M. \& Verschueren, J. (eds) (1987). The pragmatic perspective. Amsterdam: Benjamins.

Pica, P. (1984). On the distinction between argumental and non-argumental anaphors. In de Geest, W. \& Putseys, Y. (eds) Sentential complementation. Dordrecht: Foris. 185-194.

Pica, P. (1987). On the nature of the reflexivization cycle. Proceedings of the North Eastern Linguistic Society $\mathbf{1 7 .}$

Platzack, C. (1987). The Scandinavian languages and the null-subject parameter. Natural Language and Linguistic Theory 5. 377-401.

Read, C. \& Hare, V. C. (I979). Children's interpretation of reflexive pronouns in English. In Ekman, F. R. \& Hasting, A. J. (eds) Studies in first and second language acquisition. Rowley, MA: Newbury.

Reinhart, T. (1983). Anaphora and semantic interpretation. London: Croom Helm.

Reinhart, T. (1986). Center and periphery in the grammar of anaphora. In Lust. 123-150.

Rizzi, L. (1989). On the format for parameters. Behavioral and Brain Sciences 12. 355-356.

Roeper, T. \& Williams, E. (eds) (1987). Parameter setting. Dordrecht: Reidel.

Ross, J. R. (1970). On declarative sentences. In Jacobs, R. A. \& Rosenbaum, P. S. (eds) Readings in English transformational grammar. Waltham: Ginn. 222-272.

Sells, P. (1987). Aspects of logophoricity. LIn I8. $445-479$.

Sells, P., Zaenen, A. \& Zec, D. (1987). Reflexivization variation: relations between syntax, semantics and lexical structure. In Iida, M., Wechsler, S. \& Zec, D. (eds) Working papers in grammatical theory and discourse structure. Stanford: CSLI.

Sigurjonsdottir, S. \& Hyams, N. (I 988). The acquisition of reflexives and pronouns by Icelandic children. Papers and reports on child language development 27 . Stanford University.

Solan, L. (1987). Parameter setting and the development of pronouns and reflexives. In Roeper \& Williams. 189-210.

Sperber, D. \& Wilson, D. (1986). Relevance. Oxford: Blackwell.

Stirling, L. (I988). Switch-reference and logophoricity in Discourse Representation Theory. Unpublished PhD dissertation, University of Edinburgh.

Syromiatnikov, A. (198I). The ancient Japanese language. Moscow: Nanka.

Tryon, D. T. (1970). Conversational Tahitian. Canberra: ANU Press.

Ureland, S. (I98I). The development of Dutch \& West Frisian reflexives between 1879 \& 1979. In Gerritsen, M. (ed.) Taalverandering in Nederlandse dialekten. Muiderberg: Coutinho. 250-263.

Vaccari, O. \& Vaccari, E. (I948). Japanese conversation-grammar. Tokyo: Vaccari.

Van Valin, R. D. (1990). Functionalism, anaphora and syntax. A review article on Susumo Kuno, Functional syntax: anaphora, discourse and empathy. Studies in Language 14, 169-219.

Vincent, N. (1989a). Observing obsolescence. Behavioral and Brain Science I2. 360-361.

Vincent, N. (I989 b). Constituentization. Paper delivered at the Ninth International Conference on Historical Linguistics, Rutgers University, New Brunswick, August 1989.

Visser, F. T. (1963). An historical syntax of the English language. Part One. Leiden: Brill.

Wexler, K. \& Manzini, M. R. (1987). Parameters and learnability in Binding Theory. In Roeper, T. \& Williams, E. (eds). 4I-76.

Yang, D-W. (1983). The extended binding theory of anaphors. Language Research 19. I69-192. 